SOCIAL AND COGNITIVE BIASES IN LARGE GROUP DECISION SETTINGS

Emma A. Bäck

Doctoral Thesis in Psychology, Stockholm University, 2011 



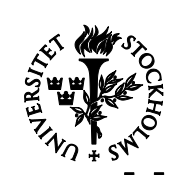

Stockholm

University

\section{Social and cognitive biases in large group decision settings}

Emma A. Bäck 
(C)Emma A. Bäck, Stockholm 2011

Cover illustration: Ivo Todorov/Emma A. Bäck

ISBN 978-91-7447-320-9

Printed in Sweden by US-AB, Stockholm 2011

Distributor: Department of Psychology, Stockholm University 
To my family! 



\section{Abstract}

The present thesis consists of three studies concerning the effects of group membership in large group decision-making. The overall aim was to contribute to the understanding of how individuals react and behave when decisions are made in large groups. We explored different consequences of procedural justice concerns within members of large groups. In the first study we investigated how different decision-making procedures and perceived issue importance affect perceptions of others who agree and disagree with the individual on a potentially important issue. Results showed that individuals attribute more positive reasons for the attitude position of those who agree as opposed to disagree with themselves, whereas disagreers were attributed more negative reasons. This asymmetry was moderated by decisionmaking form, and issue importance. The attitudes concerned attitudes towards potential new policies. In the second study we investigated how participants differed in their perceptions of others as a consequence of their own position towards the new policy suggestions and the status quo. We found that challengers of the status quo advocating a change in the existing policy, tended to be more biased in their judgments of those defending the status quo than the other way around. This suggests that challengers are less tolerant of defenders' point of view. This effect was not affected by perceptions of minority status among the challengers. In the third study we looked at individual group members' cognitive restructuring of a preferred decision alternative, and how this differs between decision-making conditions, when the decision-maker is affiliated to own ingroup or not. Results showed that individuals restructure the attractiveness of their preferred alternative in group decision-making in a similar fashion as has been previously found in individual decision-making. The magnitude of such restructuring was greatest when ingroup members decided for the group. However, this effect was moderated by identification with the ingroup, such that those who identified themselves with the ingroup restructured their preferred alternative more when ingroup members decided as opposed to when outgroup authorities decided.

Keywords: large group decision-making, social identity, procedural justice, intergroup biases, attitudes, status quo position, cognitive restructuring, post-decision consolidation 



\section{Acknowledgements}

I have always been driven by a need to understand. For this reason I applied as a research assistant in 2006 within a project that $\mathrm{I}$, at the time, was quite unfamiliar with. However, I soon discovered the depth and dimensions, and the never ending upcoming questions this job brought along. I therefore became a $\mathrm{PhD}$ student in the fall of 2006, which has led me to where I am today. I am therefore eternally grateful to my supervisor, Professor Torun Lindholm, for choosing me among many applicants for that assistant job. Torun has, with great skills, knowledge, and support, guided me through the entire process that it is to do a doctoral thesis. Besides that, she has prepared me for an academic life of my own and always been a solid support for me to turn to.

This has not been a solitary process, and I owe my thanks to many people. First, a special thank you to Professor Ola Svenson, my second advisor for help and advice with this thesis, especially on Study 3. I would also like to give a special thank you to my closest doctoral colleagues, Dr. Neda Kerimi and Anna Lindqvist, with whom I have shared both laughs and tears over the years - you are so important to me, and always ready for 'fika' and support! Thanks to Professor Peter Esaiasson and Professor Mikael Gilljam at the department of Political Science in Gothenburg for help and advice. Marie Gustafsson, Kirsti Häkkinen, Henry Montgomery, Hanna Kusterer, Marianne Jakobsson, Per-Henrik Hedberg, Ola Sternäng, Charlotte Alm; thank you for insightful ideas and rewarding discussions. I would also like to thank my reviewers Dr. Fredrik Björklund at the department of Psychology, Lund University, and Professor Bo Ekehammar. Without your comments this thesis would not have been what it is!

I am also thankful to my fellow $\mathrm{PhD}$ students for interesting discussions on weird subjects, laughter, support, and for constituting the complaint department (in no special order): Martin Arvidsson, Margareta Hedner, Håkan Andersson, Nathalie Peira, Artin Arshamian, Jesper Alvarsson, Kristina Langhammer, Ninni Persson, Veit Kubik, Anders Sand, Lars Häsänen, Malena Ivarsson, Anne Richter, Jelena Corovic, Constanze Eib, Victoria Blom, and Ivo Todorov. Please forgive me if I have forgotten anyone! Tonya Pixton, and Mats Englund; thank you for preventing an explosion towards the end of this work! It would have been sad... 
My dad, Henry Bäck, who at an early stage introduced me to the academia, my sisters Hanna Bäck and Sara Bäck, who have provided me with advice and support during my weaker moments in life, and helped me turn my life into what it is today. For that I am eternally grateful!

My grandmother, Harriet Eriksson, my brother Adam Stone and his family, Nina Stone, and Sam Stone; thank you for being you! My late mother, Mona Stone, I will never forget you, and I know how proud you are of me.

Thanks to my oldest friends, Anna Kröndahl and Johanna Jonsson, for gossiping and support, and providing a break from work. Cecilia Barkman and Lisa Jönsson, thanks for turning my time in Uppsala into one of the best times of my life, which I will never forget!

I would also like to thank Ingrid Sköldin, Malin Perez Sköldin, Inger Renström, Christer Nerving, and Hanna Renström; you always provide solid support, great food and full service!

Finally, my companion in life, Nils, for putting up with me in all weathers, never failing to provide support, taking care of 'ground support', and for giving me a new perspective in life - our beautiful son, Julian! You truly are the best that has happened to me, and I am deeply grateful to have you in my life, and love you endlessly.

Emma A. Bäck

Stockholm, August, 2011 


\section{List of studies}

The present doctoral thesis is based on the following studies:

I. Bäck, E., Esaiasson, P., Gilljam, M., \& Lindholm, T. (2010). Biased attributions regarding the origins of preferences in a group decision situation. European Journal of Social Psychology, 40, 270-281.*

II. Bäck, E. A., \& Lindholm, T. (2011). Defending or challenging the status quo: Position effects on biased intergroup perceptions. Manuscript submitted for publication.

III. Bäck, E. A., Esaiasson, P., Gilljam, M., Svenson, O., \& Lindholm, T. (2011). Post-decision consolidation in large group decisionmaking. Scandinavian Journal of Psychology, 52, 320-328.**

*This article has been reprinted with the permission of European Journal of Social Psychology, ( John Wiley \& Sons Inc.

**This article has been reprinted with the permission of Scandinavian Journal of Psychology, The Psychological Associations of Denmark, Finland, Norway, and Sweden, and Wiley-Blackwell Publishers, (C) John Wiley \& Sons Inc. 



\section{Contents}

Abstract ................................................................................. vii

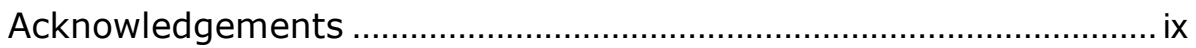

List of studies …….........................................................................

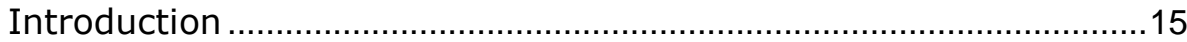

Social groups and group membership ……..................................16

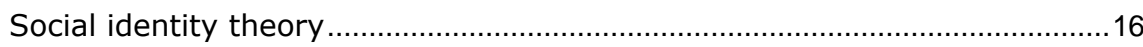

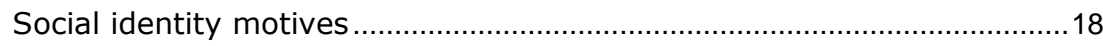

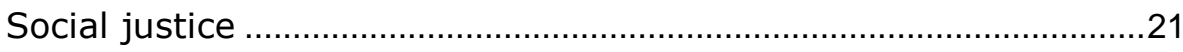

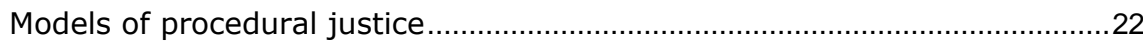

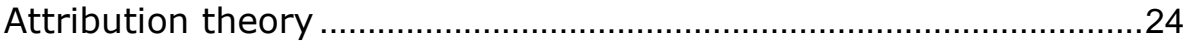

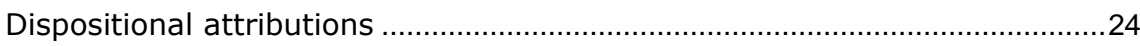

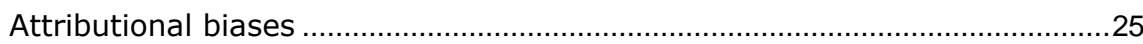

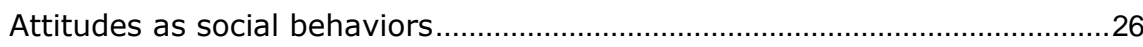

Attributional biases regarding the origins of attitudes ..............................27

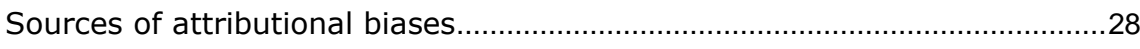

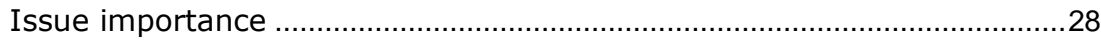

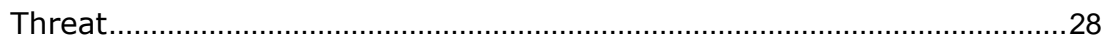

Position towards the status quo …………………………………….........29

Cognitive restructuring................................................................ 32

Representation of decision alternatives and attractiveness restructuring ....33

Measuring differentiation and consolidation................................................33

Sources of post-decision consolidation..........................................................35

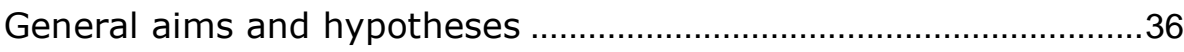

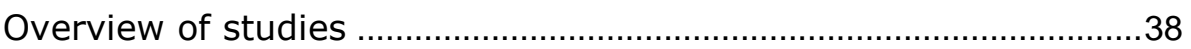

Study I: Biased attributions regarding the origins of preferences in a group

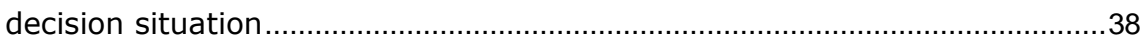

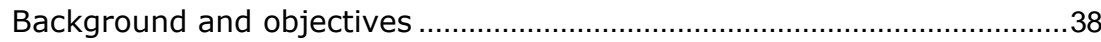

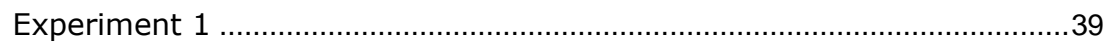

Results and discussion ...........................................................................

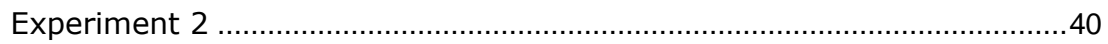




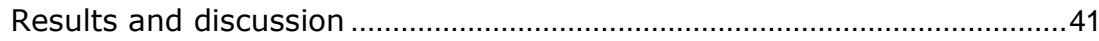

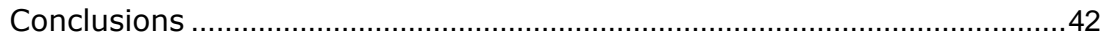

Study II: Defending or challenging the status quo: Position effects on

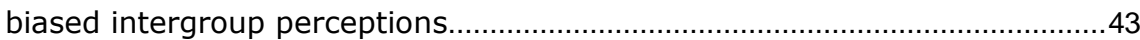

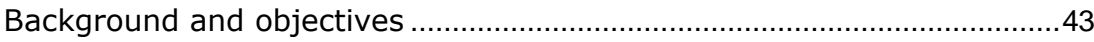

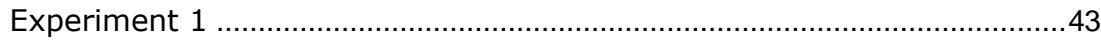

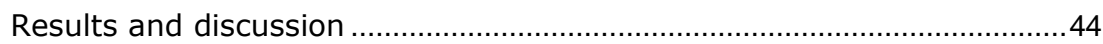

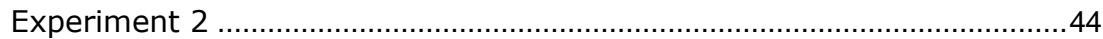

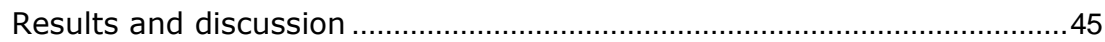

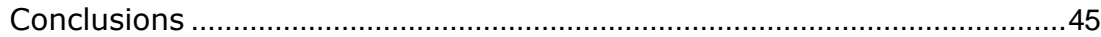

Study III: Post-decision consolidation in large group decision-making ........46

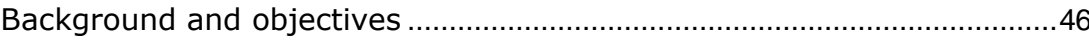

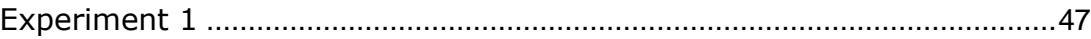

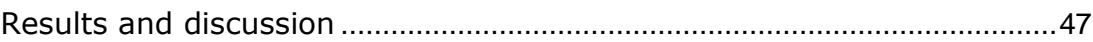

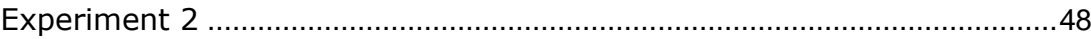

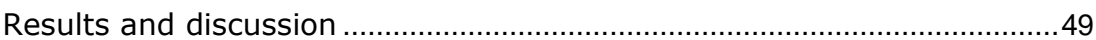

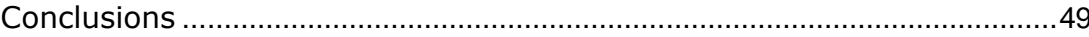

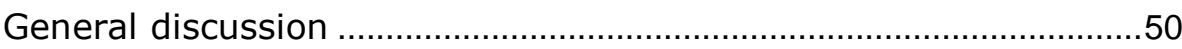

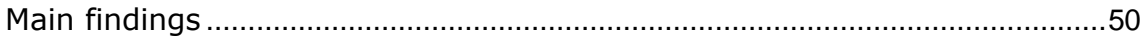

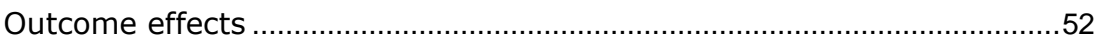

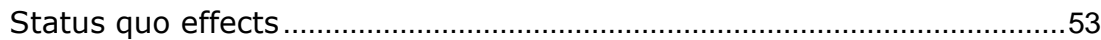

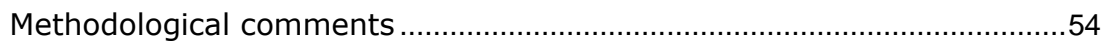

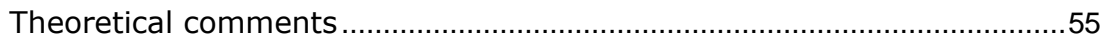

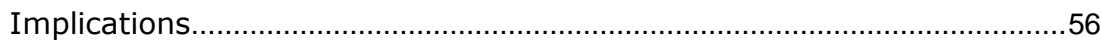

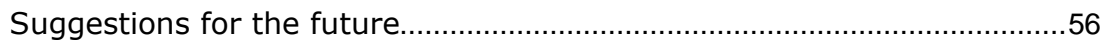

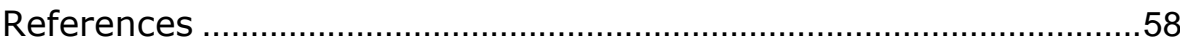




\section{Introduction}

One basic tenet of the present thesis is that people want to be part of social groups. Membership in different groups provides the basis on which people build their sense of self (Turner, Hogg, Oakes, Reicher, \& Wetherell, 1987), satisfying such fundamental needs as belonging (Baumeister \& Leary, 1995), support (Fiske, 2004), and provides a source of self-validation (Festinger, 1954; Leary, Tambor, Terdal, \& Downs, 1995). The groups that individuals belong to, based on shared attributes or attitudes, are termed ingroups, and the groups that individuals do not belong to are termed outgroups.

Such social groups may vary in size from small work groups to larger organizations and ultimately societies. Thus, the term ingroup covers a large spectrum; from all members of the group knowing each other personally to very large and anonymous groups (Brewer, 1991). The present thesis is concerned with both types of groups - larger social groups, and factions within those groups.

Often, the groups and organizations to which individuals belong have to make decisions. Such decisions will affect all group members, as for example when an organization must decide whether to implement a new policy suggestion or not. There are different ways for such a large group to reach a decision, and these different ways may, in turn, affect the members of the group in different ways. This is captured in the area of social justice research. From being mostly theories concerning the justice of distributions, justice research evolved into concerning the procedures used to reach a decision and its consequences for group members (Thibaut \& Walker, 1975).

The purpose of the present thesis is to contribute to the understanding of how large group decision procedures affect the group members in terms of tolerance for other group members, and individual cognitive mechanisms. Further, effects of preference position towards a new policy suggestion on intergroup perceptions are investigated.

Because group membership is central to this thesis, I will start by reviewing the literature on social groups and group membership. 


\section{Social groups and group membership}

As proposed by the early gestalt psychologists, people have a natural tendency to categorize the world in coherent units (Wertheimer, 1923). From this notion, some of the most influential theorists within social psychology such as Heider (1946, 1958), and Festinger (1954) developed their ideas that individuals also categorize their social world.

By structuring the social world in categories, cognitive load decrease since group membership carries important information about what to expect from others. To categorize implies separating people into discrete subgroups, and to accentuate intracategory similarities and intercategory differences. The basic processes of categorization are the same regardless of whether the objects being categorized are human beings or physical objects. From childhood, people learn to categorize objects and develop concepts that distinguish members of one category from those of another. In a similar fashion, social categorization functions equivalently to simplify, structure, and regulate understandings of, and interactions with other people. Category distinctions influence perceptions and behavior towards both individual members of the category and the category as a whole. Categories are often defined in terms of me-not me, which refer to the categories to which an individual belongs (the ingroups). In relation to the groups to which a person belongs, groups defined in terms of "not-me" refer to groups to which an individual does not belong (the outgroups). Comparisons between groups, intergroup comparisons, may then arise (Brewer, 2007a, pp. 695-696).

\section{Social identity theory}

The social categories that an individual identify with constitute a part of that individual's social identity. Psychologists sometimes distinguish between personal identity and social identity. The personal identity refers to the unique aspects of an individual's identity that are unrelated to membership in groups. The term social identity was coined by Tajfel (1978), and refers to "that part of an individual's self-concept which derives from his knowledge of his membership of a social group (or groups), together with the value and emotional significance attached to that membership" (p. 63). This definition implies that what is necessary for social identity is the psychological value, the feeling of connectedness, and emotional investment to the groups to 
which an individual belongs. The group(s) must be an important part of how an individual defines him/herself. To the extent that an individual identifies with a given group, that group becomes a part of that individual's social identity and thus also a part of that individual's self-concept. The essential criterion for group membership is that an individual defines him/herself, and is defined by others, as a member of the particular social group (Tajfel \& Turner, 1979).

Mere categorization elicits social identification and intergroup differentiation, more commonly known as minimal groups (Tajfel \& Turner, 1986). When an individual create social categories of others into ingroups and outgroups, they spontaneously experience positive affect towards the ingroup and engage in behaviors that benefit the ingroup as a whole and its individual members (Tajfel, Billig, Bundy, \& Flament, 1971; Piliavin, Dovidio, Gaertner, \& Clark, 1981). Because individuals identify themselves according to the attributes they possess, such as gender, age, and nationality, such attributes create the foundation for categorization and thus for group membership.

However, social groups may, according to the above definition, not have to be that overt. This implies that less obvious attributes, such as attitudes and opinions, could also create social categories (Kenworthy \& Miller, 2002; Biernat \& Vescio, 1993). For example, the boundaries of political groups such as political parties are based on shared and non-shared attitudes. The claim that attitudes can be seen as group boundaries, and thus that such groups will be defined in terms of social identity theory, was further investigated by Kenworthy and Miller (2002). A group may be defined according to its entitativity, which essentially is the extent to which individuals "are perceived as being bonded in a coherent unit" (Lickel et al., 2000, p. 224). The entitativeness of naturally occurring groups (e. g. Americans, people of the same fraternity) was compared with groups based on attitudes (e. g. prolife/pro-choice on the abortion debate). Many of the groups based on attitudes were actually perceived as higher in entitativy than were the natural groups. Thus, individuals tend to perceive others, who share their own attitudes as their ingroup, and others who do not share their position as their outgroup (Kenworthy \& Miller, 2002). For the present thesis this is an important point to be made, as these are the kind of groups investigated and thus that attributions between such groups reflect social identity concerns. Consistent through all studies, groups bounded by attitude position are examined.

When a particular social identity is made salient, individuals are likely to think of themselves as having characteristics that are representative of that category implying that social identity leads to self-categorization (Hogg \& Turner, 1987; Turner et al., 1987). Traits that are typical for the group become central to the self-concept when that social identity is activated (Brewer, 2007a). Ingroup positivity is considered the hallmark of ingroup identification and is consistently found on attributes that are self-relevant (Otten, 
2002), and traits that reflect basic social values such as trustworthiness and cooperativeness (Brewer, 2001; LeVine \& Campbell, 1972).

Own identity is closely connected to group membership, and members see themselves as having characteristics that are representative of the group. Ingroup identification in turn leads to ingroup favoritism; positive affect towards the ingroup which is automatically activated (Brewer, 2007a). A positive ingroup image is achieved by systematically altering perceptions of reality in favor of the own group (Allport, 1954; Brewer, 2007a; Perreault \& Bourhis, 1999; Tajfel et al., 1971).

\section{Social identity motives}

Because identification with groups is central to this thesis it is important to understand what the motives are that drive identification. Several motives to why individuals identify with groups have been proposed. Social identities that satisfy psychological motives are perceived as more central to the way individuals see and define themselves (Vignoles, Regalia, Manzi, Golledge, $\&$ Scabini, 2006). In the following I review some of these that are of importance for the present thesis.

\section{The self-esteem motive}

As pointed out by Tajfel and Turner (1979), people strive to maintain or enhance their self-esteem, a positive self-concept. This implies that individuals strive to maintain or achieve a positive social identity (p. 16). Belonging to highly regarded groups may satisfy both personal and collective selfesteem. Personal self-esteem is, as personal identity, relevant to an individual's perceptions of his/her own skills, abilities or intelligence (Tajfel, 1978). Collective self-esteem refers to self-esteem at a group level, a collective selfimage, and increased collective self-esteem thus implies that an individual evaluates him/herself positively as a group member rather than as an individual (Crocker \& Luthanen, 1990; Rubin \& Hewstone, 1998). To the extent that people derive heightened self-esteem from belonging to certain groups, their identification with the social group will increase, and thus individuals will strive to be members of high status groups.

\section{The motive to belong and the distinctiveness motive}

As noted in the introduction, humans have a fundamental need, a psychological drive, to belong to groups (Baumeister \& Leary, 1995). In order to belong to a group, individuals identify themselves with that group. This need to belong (also implies fear of rejection, which repeatedly has been shown to affect individuals negatively Baumeister \& Leary, 1995). In the face of possible rejection individuals respond in ways they believe will establish their group identity or they seek acceptance from other groups to feel inclusion (Williams, 2007). 
Whereas the need to belong is an important driving force to seek out membership in groups, individuals also have a need to feel unique and distinct (Brewer, 1991, 2007b). Distinctiveness between the own group and other groups is necessary for group categorization - for the boundaries between 'us' and 'them', and thus also for inclusion. Thus, belongingness and distinctiveness are two opposing social needs that go hand in hand. These opposing social needs; the need to belong and the need for distinctiveness have been extensively studied by Brewer $(1991 ; 2007 b)$ and consolidated into a theory of optimal distinctiveness. According to this theory, individuals belonging to groups of optimal size, that is, groups that satisfy both of these needs, are those who are most highly identified with their group, and thus also exhibit the highest levels of loyalty, conformity, and cooperation (2007b). A group of optimal size is one that is "sufficiently large and inclusive to realize the advantages of extended cooperation, but sufficiently exclusive to avoid the disadvantages of spreading social interdependence to thin" (Brewer, 2007b, p. 731). In contrast to the self-esteem motive, where ingroup positivity derives from positive distinctiveness from other groups, optimal distinctiveness theory posits that self-esteem is secondary. The primary driving force is the satisfaction of fundamental security needs for belonging and distinctiveness (Brewer, 2007b).

\section{The motive to reduce uncertainty}

It has been known for a long time that people are sensitive to the preferences and opinions of others, because others' preferences may be utilized as information to what is correct (Festinger, 1954; Kelley, 1967). Thus, if people feel uncertain, they can turn to others to receive information about what is correct and appropriate. Because groups provide norms and prototypes for how the members should feel, think and behave, groups also function to reduce uncertainty in that aspect (Hogg, Hohman, \& Rivera, 2008). In this respect, highly entitative groups, groups perceived as a coherent entity, should provide most uncertainty reduction (Campbell, 1958; Hamilton \& Sherman, 1996; Hogg, 2006). This motive differs from the previous ones in that it is not as fundamentally social, but is rather driven by a motivation for being correct. It is nevertheless important to mention here, as it may have consequences for how individuals perceive others, especially if others validate own attitudes, which contributes to the group's entitativeness.

\section{Summary}

In sum, given the above, it is clear that group memberships are important aspects of an individual's life. Group memberships provide the basis for the self-concept (Tajfel \& Turner, 1979; Turner et al., 1987), and satisfy the fundamental needs of belonging (Baumeister \& Leary, 1995; Brewer, 1991), distinctiveness (Brewer, 1991), support (Fiske, 2004), and self-validation (Festinger, 1954; Leary, Tambor, Terdal, \& Downs, 1995). Hence, people 
want to belong to groups, and people are sensitive to cues of rejection (Williams, 2007).

Clearly, being a member of a group will give rise to consequences for how individuals perceive themselves and others who are members of the same or other social groups. The more individuals identify with a group, the more they will differentiate themselves from other groups leading to stereotypical perceptions of others (Perreault \& Bourhis, 1999). This is the theoretical point of departure for the present thesis.

Identification with a group does not appear randomly. Rather some factors have been consistently found to affect the extent to which members of a group identify with their group, and thus also the extent of group-serving behaviors displayed by the members. The extent to which members perceive that they receive fair treatment and respect from group authorities and other group members within the group affect identification, and group-serving behaviors. This is especially important in decision situations, which is to be investigated in the present thesis. 


\section{Social justice}

As mentioned in the introduction, it is not uncommon that groups need to make decisions that will affect all of the members, for example in business companies or other organizations, and in democratic decisions. Research on group decision-making has been largely directed to the area of small group decision-making (Janis \& Mann, 1977). However, during the 1970s, researchers started investigating the field of larger group decision-making and justice (Walster, Walster, \& Berscheid, 1978). In the beginning, this research was concerned with perceptions of fairness regarding outcome distributions. However, attention was later turned towards the importance of procedures over outcomes (Thibaut \& Walker, 1975; Alexander \& Ruderman, 1987).

During the last decades, much of the research on decision-making in larger groups has focused on procedural justice, that is, how a decision in a larger group is reached. The choices of procedures have repeatedly been shown to have a profound impact on group members.

Procedures specify authority relations, and authority relations are potent determinants of the individuals' behavior (Lind \& Tyler, 1988). When procedures are in accord with fundamental values of the group and the individual, a sense of procedural justice emerges. Because procedures are important aspects of a group, evaluations of procedures are expected to have important implications for group relevant attitudes and behaviors. If procedures are considered unfair, commitment and positive attitudes towards the group will suffer (Lind \& Tyler, 1988). Within this tradition then, research implies that the procedures used to reach a decision in a group will affect the individuals' feelings and actions (Tyler, Degoey, \& Smith, 1996). For example, previous research shows that when individuals perceive that they have been treated fairly during a decision-making process they are more willing to accept the final decision outcome (Lind, Kulik, Ambrose, \& de Vera Park, 1993), are more likely to comply with the group's values (Tyler, 1990; Tyler \& Degoey, 1995), are more willing to remain a group member (Brockner, Tyler, \& Cooper-Schneider, 1992; Tansky, 1993), and are more willing to help the group, even at a personal cost (Tyler \& Degoey, 1995). These are all important implications from procedural justice research. 


\section{Models of procedural justice}

Over the years, several models of procedural justice have been proposed. The common notion that runs through all of these is that treatment by authorities and other group members in a group decision process has implications for the individual's self-perceptions. In the following section I will review aspects of three models of procedural justice that are of importance for the present thesis; the group value model of procedural justice (Lind \& Tyler, 1988), the relational model of authority (Tyler \& Lind, 1992), and the group engagement model (Tyler \& Blader, 2003).

The group value model of procedural justice (Lind \& Tyler, 1988), and the relational model of authority (Tyler \& Lind, 1992) build on social identity theory. Specifically, they utilize the social identity premise that individuals use groups, and their authorities, as a source of information about their self-worth (Hogg \& Abrams, 1988; Tajfel \& Turner, 1986). This is done because authorities of a group are seen as prototypical members, or representatives of the group, and their behavior is indicative of the whole group's attitudes and opinions (Hogg \& Abrams, 1988; Tyler \& Lind, 1992).

Thus, procedures and treatment inform members of their social connection to their groups and group authorities, in particular, the degree to which they are respected members of their groups. Whereas fair treatment signals respect, unfair treatment signals disrespect. Respect is the first important message sent to group members by fair treatment (Tyler, Degoey, \& Smith, 1996). To illustrate, imagine the following; An employee that is treated unfairly by his/her boss, perceives this as a signal that he/she is not a valued and important member of the workforce. In contrast, an employee treated with dignity and respect, perceives this as a signal that he/she is a valued and important part of the workforce. This leaves the employee with a positive self-image, feelings of being respected and feelings of pride of the group membership - being part of this particular workforce. Such feelings of pride in group membership are the second important message transmitted by fair treatment from authorities (Tyler, Degoey, \& Smith, 1996). The group engagement model predicts that feelings of pride and respect lead to increased identification with the group, and this in turn increases group-serving behaviors, such as cooperation with the group (Tyler \& Blader, 2003).

Thus, individuals care about the procedures because procedures shape their social identity within the group (Tyler \& Blader, 2003). Moreover, individuals are most concerned with procedures when the decision-makers belong to a valued ingroup (Lind \& Tyler, 1998; Tyler \& Lind, 1992), whereas outgroup authority treatment is less important for self-perceptions (Smith, Tyler, Huo, Ortiz, \& Lind, 1998). This was investigated by Smith and colleagues (1998) who showed that students receiving test feed-back from a grader affiliated with their own university (an ingroup authority) felt more respected in a high treatment quality condition as opposed to a low treatment quality condition (the grader was thorough and involved as op- 
posed to sloppy and uninvolved). When the grader was from a different university (an outgroup authority), there was no difference in feelings of respect between the treatment quality conditions.

Extending research on the group engagement model, several authors have argued that because outgroup treatment does not signal self-relevant information, individuals tend to focus on the outcomes instead of procedures in encounters with outgroup authorities (Huo et al., 1996; Duck \& Fielding, 2003; Ståhl, van Prooijen, \& Vermunt, 2004). However, if outcome information is ambiguous rather than evident, individuals will care more about procedures from outgroup authorities (Ståhl et al., 2004).

In sum, treatment is more important than outcome when decisions are made by ingroup authorities, but outcome is more important when the decision is made by outgroup authorities, unless the outcome is ambiguous. In addition it is clear that (fair) procedures affect group-serving behaviors such that the ingroup is favorised and perceived more positively. In the current thesis, a main goal is to investigate the effects of different decisionprocedures in relation to perception of others, when the groups are constituted of attitude position.

As stated by Social identity theory, identification leads to group differentiation (Tajfel \& Turner, 1979), such as ingroup favoritism and outgroup derogation (Brewer, 2007). According to the group-value model (Tyler \& Blader, 2003), when members of a group are treated fairly, identification, and thus also group-serving behaviors increase. Such biased attitudes and behaviors are captured within an attribution theoretical framework. Thus, social identity is the common thread that runs through both social justice, and attribution theory. 


\section{Attribution theory}

Because group membership shapes an individual's perception of other group members and members of other groups, the way members explain other's behaviors may also depend on group memberships. Attribution is the process by which individuals explain the causes of their own and others' behaviors, and infer characteristics of other individuals (Fiske \& Taylor, 2008, p. 134). An early insight from research on attribution processes is that individuals do not spend time and effort researching for the best possible explanation for an event, but rather usually seize upon the most readily accessible, single, sufficient explanation for the particular situation at hand (Jones \& Davis, 1965; Fiske \& Taylor, 2008).

\section{Dispositional attributions}

Much of the causal reasoning individuals engage in is related to explaining the behaviors of others. In order to control, understand, and predict the behaviors displayed by others, individuals strive to infer dispositions to observed behaviors, such as beliefs, traits, and abilities (Heider, 1958). According to Heider (1958), individuals strive for a balanced state, which is achieved when an action and a disposition are in harmony. For example good people perform positive actions. In general, Heider (1958) distinguished between two categories of explanations that individuals give for the actions of other people; internal and external. Internal attributions implicate that a person performs an action because of personal characteristics, such as ability, attitudes, and effort. External attributions, on the other hand, implicate that events or outcomes occur because of factors external to the individual, such as the influence of other people, luck or task difficulty.

Inspired by the work of Heider, Jones and Davis (1965) developed a theory of correspondent inferences. The theory aims to account for the intentions of an actor's observed behavior. Correspondence refers to the extent that the act and the underlying characteristic or attribute is similarly described by the inference (Jones \& Davies, 1965, p. 223). If an action can be explained in terms of personal characteristics correspondence of inference is high, however correspondence declines if the action is seen as constrained by the context in which it occurs (Jones \& Davis, 1965). Thus, the term correspondence carries some similarity to Heider's notion of balance. Another 
common ground between these theorists is that actions may be explained either in terms of personal characteristics or contextual characteristics - a notion that is still at the heart of attribution research. However, Jones and Davis made it clear that the attribution process was not as deliberate as Heider presented it, but rather fast and unreflected, seeking a sufficient explanation for an observed action (Jones \& Davis, 1965, p. 220). This has later been thoroughly researched. For example, individuals make snap dispositional inferences based on group attributes, such as appearance, gender, race and age (Willis \& Todorov, 2006). Even though it turns out that these fast, unreflected judgments are quite often correct (Todorov, Mandisodza, Goren, \& Hall, 2005), providing a solid base for future inferences, it is understandable that people will make mistakes in their inference judgments of others. Further, such mistakes are not random, but rather systematic.

\section{Attributional biases}

There are a number of well-known errors, or biases, that individuals commit when inferring the causes of their own and other people's behaviors. One of the most well known examples is the tendency to represent oneself more positively than others. When explaining own behavior, individuals tend to ascribe more situational factors as causes, especially for negative behaviors, whereas other people's behaviors are usually attributed to their dispositions. This means that individuals make excuses (for example time-pressure) for their own negative behavior (snapping at someone), whereas the same negative behavior displayed by another is interpreted in terms of that person's character (an unfriendly person). This bias is called the actor-observer effect (Jones \& Nisbett, 1972). However, actor-observer differences have been shown to be very small (Malle, 2006), and the effects differ when the event's valence is negative. Further, individuals explain their own behavior in terms of observers under some circumstances, for example when explaining their past or future behaviors (Pronin \& Ross, 2006). In addition, there are cultural differences showing that in collectivistic cultures, individuals are much more attentive to the environment when explaining the behaviors of others, thus not falling prey to the actor-observer asymmetry (Chua, Leu, \& Nisbett, 2005).

Even though the actor-observer effect has been debated it has spurred a lot of research. For example, Miller and Ross (1975) showed that when it comes to positive behaviors, individuals are more likely to attribute these to their own personal characteristics. This bias extends to apply to the individual's ingroups and is the core of ingroup favoritism (Pettigrew, 1979; Tajfel \& Turner, 1986; Robbins \& Kreuger, 2005), the hallmark of ingroup identification (Brewer, 2007). Individuals tend to attribute positive behaviors of members of their ingroups to positive ingroup qualities, whereas negative beha- 
viors displayed by ingroup members are attributed to external causes (Pettigrew, 1979; Brewer \& Brown, 1998); a phenomenon called the ultimate attribution error. These self-serving and group-serving biases are explained by both cognitive and motivational factors. To present one-self and one's ingroup positively have positive consequences for psychological well-being (Brewer, 1991; Fiske \& Taylor, 2008).

\section{Attitudes as social behaviors}

The explanations that individuals give for other's behaviors may themselves be seen as social behaviors that need to be explained (Malle, 1999; Malle \& Knobe, 1997). Kenworthy and Miller (2002) argue that attitudes, regardless of whether causing or explaining behaviors, when expressed, are themselves social behaviors that need explanation. They go on stating that attitudes, even though they can be seen as explanations for behavior, can also be seen as meaningful social phenomena that can be explained in a variety of ways using an attributional approach (Kenworthy \& Miller, 2002, pp. 639-694).

In order to understand how individuals explain, or attribute the attitudes and attitude positions of others, Kenworthy and Miller (2002) conducted a pilot study, interviewing participants about their perceptions of the sources of their attitudes. This study was based on research on the affectivecognitive bases for attitude structures (Chaiken, Pomerantz, \& Giner-Sorolla, 1995; Eagly \& Chaiken, 1998; Zanna \& Rempel, 1988). This research has shown that there are two primary bases for an attitude position. First, there is an affective component, implying that the position an individual holds derives from how that person feels about the position. Second, there is a cognitive component, implying that the position derives from an objective evaluation of facts, or a rational examination of the characteristics of an object, person, or event (Eagly \& Chaiken, 1998). From a factor analysis of the explanations provided for the attitudes, Kenworthy and Miller (2002) explored three dimensions for how individuals explain their attitude positions in a number of issues (abortion rights, legalization of medicinal marijuana, and capital punishment). The three dimensions found were externality, rationality, and emotionality. External sources include influence from family, parents, news, and friends, indicating that individuals believe that others may hold an attitude because of such external sources (Kenworthy \& Miller, 2002). Further, in line with the cognitive component underlying attitude formation, an attitude may be perceived to be based on internal or personal reasons. This dimension is characterized by responses such as thinking or rationality (e. g. "thought about the topic and came to the conclusion", "it makes logical sense"). Such arguments are in agreement with previous research. Huskinson and Haddock (2004) argue that an attitude may be held because of rational reasons, such as reasoning and rational thought derived through independent thinking and weighting of alternatives. Thus, this di- 
mension is labeled rationality. The last dimension is characterized by responses related to the affective component underlying attitude formation, labeled by Kenworthy and Miller (2002) as emotionality (e. g. "feels good to hold the opinion", "emotionally reassuring"). This argument also receives support from recent research. Maio and Haddock (2007) argue that an attitude may be held due to emotions connected to the attitude position, as a way of experiencing emotions.

\section{Attributional biases regarding the origins of attitudes}

The dimensions derived by Kenworthy and Miller (2002) differ in their social desirability. For example, it is more socially desirable to hold an attitude because of rational reasons than because of external or emotional factors. This asymmetry creates the foundation for self- and group-serving attributional biases when explaining both own and other's attitude position. Kenworthy and Miller (2002) showed that individuals tend to attribute their own attitudes in the most favorable fashion (most rational, least external, and least emotional) followed by their ingroup, constituted of others holding the same attitude as the individual him/herself. The outgroup, constituted of individuals holding an opposite attitude position to the participant was evaluated most negatively (least rational, most external, and most emotional). Given Kenworthy and Miller's (2002) argument that attitude position constitutes group boundaries, creating an in- and an outgroup, these findings are in line with what would be expected from social identity theory in a group serving perspective.

An alternative explanation to why individuals explain the attitude in this self- and group-serving way comes from Ross and Ward (1996). Their theory on naïve realism is rooted in people's inability to change perspectives (Ross \& Ward, 1996). Naïve realism is the tendency for individuals to believe that (1) the way they see entities and events are objective reality, and that their own social attitudes and beliefs follow from relatively unbiased apprehension of the information or evidence at hand, and (2) that other rational social perceivers generally will share one's own view - provided that they have access to the same information, and that they too have processed this information in a reasonably thoughtful and open-minded fashion, and (3), that the failure of any given individual or group to share one's own views arises from one of three possible sources - (a) the individual or group has been exposed to a different sample of information, (b), the individual or group in question may be lazy, irrational, or otherwise unwilling to proceed in a normative fashion from objective evidence to reasonable conclusions, or (c) the individual or group in question may be biased by ideology, selfinterest, or some other distorting personal influence (Ross \& Ward, 1996, pp. 110-111). For example, Pronin and colleagues (2004) showed that individuals tend to ascribe a higher susceptibility to bias to other people, especially if these others disagreed with them. Naïve realism further suggests that indi- 
viduals believe that they know other people better than other people know them, resulting in an illusion of asymmetrical insight (Pronin, Kruger, Savitsky, \& Ross, 2001). Hence, the results found by Kenworthy and Miller (2002) are also in line with what would be predicted by naïve realism.

The attribution of externality and rationality to the in-and outgroup will be investigated further in this thesis. The emotionality dimension yielded mixed results in their studies, and Kenworthy and Miller (2002) argue that the implications of ascribed emotionality are not clear. Hence, the choice was made not to include this dimension.

In the present thesis, we will extend further upon the results found by Kenworthy and Miller (2002), by considering some alternative sources to explain variation in the strength of such biases.

\section{Sources of attributional biases}

Besides the fact that simply belonging to different groups elicits intergroup differentiation and attributional biases (Tajfel \& Turner, 1986), a number of other sources are relevant to discuss in relation to this thesis.

\section{Issue importance}

Reeder et al. (2005) have confirmed that individuals attribute more negative motives to disagreeing others than to agreeing others. More importantly, in one of their experiments (Experiment 4) they also found that this effect was moderated by how important the attitude issue was considered to be. Participants highly involved in the issue perceived more negative motives in others with dissimilar attitudes than their own, than participants who were less involved in the issue. According to Reeder and colleagues (2005), it can be assumed that those who are most involved in an issue are those who are most likely to identify with others who share their attitudinal position. From this it can be expected that the same individuals are those who are highly motivated to differentiate between the groups. Thus, these results are in line with social identity theory, stating that when an individual identifies highly with a group, intergroup differentiation and group-serving behaviors increase (Tajfel \& Turner, 1986; Perreault \& Bourhis, 1999). In this thesis, we will extend the results by Kenworthy and Miller (2002), and Reeder et al. (2005) by integrating their results in one study, and, at the same time using a social justice framework.

\section{Threat}

Similar to the way cues of rejection motivate individuals to re-establish group membership (Williams, 2007), other types of social threat has been 
shown to affect group-serving behaviors (Bettencourt, Miller, \& Hume, 1999; Branscombe \& Wann, 1994; Stephan et al., 2002). When individuals perceive that their social identity is threatened they become motivated to enhance or protect their group and group membership by increasing attributional biases. In experiments manipulating threat to social identity, outgroup derogation increases (Branscombe \& Wann, 1994) and individuals form more extreme and homogeneous perceptions of outgroup members (Corneille, Yzerbyt, Rogier, \& Buidin, 2001). Kenworthy and Miller (2002) also showed that when individuals are socially threatened they differentiate more between their in- and outgroup on the attitude dimensions of rationality and externality. A common way to manipulate social threat is by informing participants that their own attitude position is either shared by the majority or the minority. This is based in the implication that belonging to the majority indicates having the correct attitude, and belonging to a minority may indicate having an incorrect attitude, which could threaten an individual's positive image of both oneself (Festinger, 1954; Tesser, 1988), and one's ingroup (Tajfel \& Turner, 1986). In line with this, it has been shown that when an individual lacks support for his/her own preference, the individual may expect his/her preference to be questioned (Brehm \& Mann, 1977; Hammarberg \& Svenson, 2000), and that constitutes a threat to own attitude position.

According to the models of social justice reviewed above, ingroup authority decisions are of more importance to self-perceptions, than are outgroup authority decisions (Tyler \& Blader, 2003). This is because ingroup treatment has consequences for how an individual identifies with the group. Thus, it is possible that when ingroup authorities decide, individuals may perceive a higher potential identity threat, which may elicit biases. Hence, it is expected that intergroup biases will vary with different decision-making forms. In particular, group-serving behaviors such as attributional biases should increase, when ingroup authorities decide. This is one key issue that the current thesis aims to investigate.

In a group-decision, a discordant outcome constitutes a threat towards personal interests and conveys information that others may not share own preference, again implying that one's own position may be incorrect, thus possibly increasing biases. The role of decision outcome is a further question that will be examined in the present thesis.

\section{Position towards the status quo}

The studies reviewed so far regarding the origins of attitudes (Kenworthy \& Miller, 2002; Reeder et al., 2005) concerned the explanation of attitudes towards certain social issues (e. g., attitudes towards abortion, medicinal marijuana, and gay marriage), but not towards the possible implementation of new policies per se, that is, towards the status quo.

The default ideological position is status quo maintaining (Skitka, et al., 2002). Research show that those who want to maintain the status quo are 
perceived more positively, in contrast to individuals striving to overhaul the status quo, whom are usually perceived more negatively (O'Brien \& Crandall, 2005). Schweitzer (1994) argued that giving up the status quo might be perceived as a loss, whereas changing the status quo may be perceived as a gain. Because losses are more averse than gains of equal magnitudes (Kahneman \& Tversky, 1982), individuals are willing to invest more in order to defend the status quo, than they are in order to change it. Such an argument would imply that defenders should exhibit more negativity towards challengers than the other way around. For example, O'Brien and Crandall (2005) suggest that when an individual's arguments challenge the status quo, the naïve realist perceives that advocate as driven by self-interest not seeing the world as it objectively is.

Even though the aforementioned research indicates that individuals in general want to maintain the status quo, there are still those who choose to challenge it. With enough motivation and cognitive effort, people can override the status quo preference (Skitka et al, 2002). For example, many minority groups engage in system overhauling activities. From a naïve realism perspective (Ross \& Ward, 1995), these individuals should also believe that their perception of the world is the correct one, and that defenders of the status quo are the ones exposed to biases.

Actively choosing to challenge what is generally considered to be good and true should be accompanied with an increased risk of being criticized, and thus a threat to one's own positive self-image. Hence, being a challenger should be associated with a higher social cost, than being a defender. In addition, being a defender may imply being in the majority and having the correct opinion, which should lessen the need to justify own position. In line with this, several authors have pointed out that challengers of the status quo are in a vulnerable and exposed position (De Dreu, Kluwer \& Nauta, 2008; O'Brien \& Crandall, 2005). This argument implies that challengers of the status quo should be more biased in their perceptions of their allies and opponents than should defenders. Some support for this is given by De Dreu and colleagues (2008, Experiment 2), who showed that challengers perceived defenders as less friendly and more dominant than the other way around, indicating that challengers of the status quo actually showed more intergroup biases than did defenders. It is still unclear how status quo position affects on intergroup perceptions of in groups constituted of attitude position. This issue is investigated in the current thesis.

In sum, three possible sources of intergroup biases will be more closely examined in the studies included in the present thesis: issue importance, position towards the status quo, and factors related to threat. This kind of integration of sources is not found in previous research. Group-serving behaviors and attitudes will be studied using a social identity framework, including social justice, connecting the three large theoretical areas reviewed until this point of the thesis. However, before tying up the knot, a final point has to be made. In relation to attitude position, an individual decision regard- 
ing what position to take, must be done. The final study has the purpose of integrating group decision-making with cognitive processes at the individual level that takes place during and after the individual decision. 


\section{Cognitive restructuring}

The present thesis is primarily concerned with group decision-making. Decisions take place in a social context as outlined in the previous sections. Different kinds of social settings trigger different kinds of behaviors in the individuals who are parts of the settings. Therefore it is important to investigate how individual cognitive processes operate in these settings. In order to fully understand how such processes may be affected by group dynamics, I will first review the literature on individual cognitive decision processes with an emphasis on descriptive decision theory and empirical findings.

In the first stage of making a decision, a person is exposed to the decision problem, and its alternatives. The purpose of a decision process is to select one of two or more decision alternatives that is sufficiently superior to the other(s) in order to make a final decision. According to Svenson (1996) this is achieved in a pre-decision differentiation process.

Several authors have proposed that post-decision processes seem to affect individual actions and attitudes (Festinger, 1964; Janis \& Mann, 1977; Simon, Snow, \& Read, 2004; Brownstein, 2003; Russo, Carlson, Meloy, \& Yong, 2008; Svenson, 1996, 2006). After a decision is made, a state of discomfort may arise, because the decision-maker has to put up with the negative features of the chosen alternative, whereas the positive features of the non-chosen alternative will be lost (Festinger, 1957, 1964). To reduce such discomfort, the decision problem may be restructured and the alternatives bolstered such that the chosen alternative's evaluation is increased, and/or the non-chosen alternative's evaluation is decreased - the chosen alternative is bolstered, and the alternatives are spread wider apart from a pre- to a postdecision phase (Festinger, 1964; Janis \& Mann, 1977; Simon et al., 2004; Brownstein, 2003; Russo et al., 2008; Svenson, 1996, 2006). One of the functions of such restructuring is to create a decision alternative that can withstand future threats that could challenge the superiority of the chosen alternative (Festinger, 1964; Svenson, 1996). This process has been labelled post-decision consolidation (Festinger, 1964; Svenson, 1996).

The way such a decision process operates may be paralleled with the social psychological notion of wanting to be consistent over time even if attitudes change (Ross \& Shulman, 1973). To achieve consistency, memories of past behaviors and events may be altered to fit current attitudes (Ross, McFarland, \& Fletcher, 1981). Similarly, post-decision restructuring may function to keep an earlier decision in line with current attitudes (Conway \& 
Ross, 1984), and thus keeping the superiority of the chosen alternative intact even if its relative advantage may be reduced (Svenson, 1992).

\section{Representation of decision alternatives and attractiveness restructuring}

\section{Measuring differentiation and consolidation}

The measurement of these complex decision-processes deserves some attention. In order to measure pre-decision differentiation participants rate the attractiveness of the most important attribute on both the preferred and the non-preferred alternative, before their final decision. An example is illustrated in Figure 1, where "value" is synonymous with attribute. In this case the decision regards whether teachers in schools should be allowed or not allowed to confiscate students' cell phones during class hours if they are considered disturbing. As can be seen in Figure 1, for this, most important attribute - to create a good learning environment - attractiveness ratings tend to favor the first alternative; that teachers should be allowed to confiscate cell phones. The differentiation is then calculated by subtracting the attractiveness rating (the distance measured in millimeters from the left anchor to the marking) of the non-preferred alternative from the preferred alternative, which they have already stated prior to the attractiveness assessment.

Value 1: Create a good learning environment

Alternative 1

Teachers should be allowed to confiscate disturbing cell phones

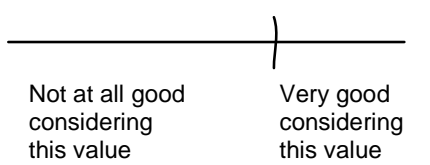

Alternative 2

Teachers should not be allowed to confiscate disturbing cell phones

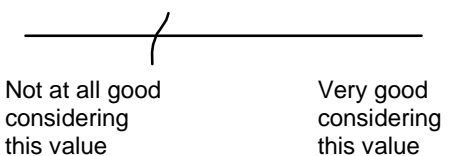

Figure 1. Picture of pre-decision ratings for the preferred and non-preferred alternatives. 
This pre-decision differentiation has now left the decision-maker with an alternative that is sufficiently strong to make a final decision. After this final decision is made, the decision-maker's internal processes continue to work on the prior decision. After some time has elapsed, the same attractiveness ratings are assessed once again, which are now increased/decreased such that the alternatives are spread wider apart. This is illustrated in Figure 2 below. As can be seen, compared to Figure 1, the attractiveness ratings in Figure 2 are now closer towards the end points of the scales, indicating that both enhancement of the attractiveness of the chosen alternative and reduction of the attractiveness of the non-chosen alternative has occurred.

\section{Value 1: Create a good learning environment}
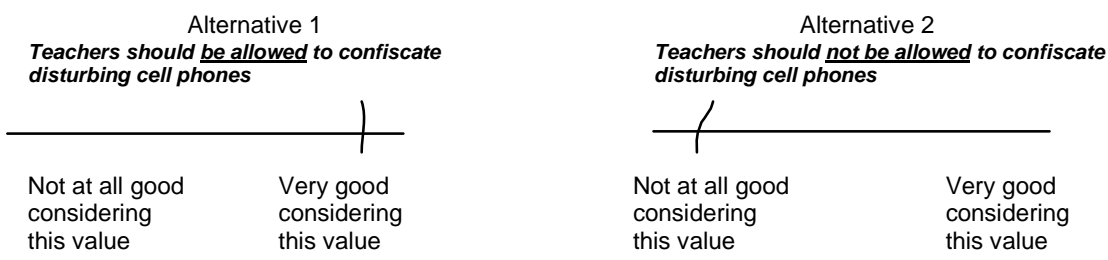

Figure 2. Picture of post-decision ratings for the preferred and non-preferred alternative.

The differentiation between the attractiveness ratings for the chosen and non-chosen alternatives is calculated as previously, resulting in a predecision, and a post-decision differentiation. The change in attractiveness ratings from a pre- to a post-decision phase is the process referred to as postdecision consolidation. The spreading of alternatives continue after a decision is made because the decision-maker may be faced with threats to the chosen alternative, such as cognitive dissonance (Festinger, 1964) or regret (Loomes \& Sugden, 1982) surfacing when the decision-maker realizes that the good aspects of the non-chosen alternative are lost and the bad aspects of the chosen alternative are a fact (Svenson, 2003).

In contrast to previous research investigating post-decision processes, the current approach is contingent on evaluations of specific attributes rather than holistic evaluations of alternatives. This provides a more nuanced measure. As some attributes may contradict each other, the holistic evaluation may remain unchanged from a pre- to a post-decision phase even though attractiveness restructuring may indeed have occurred (Svenson, 1996). 


\section{Sources of post-decision consolidation}

In general, some aspects of a decision situation will affect the magnitude of consolidation. For example time pressure has been shown to weaken differentiation and/or immediate consolidation (Benson, 1993). Of particular importance for the present thesis, two aspects that affect consolidation are involvement and uncertainty. A prerequisite for post-decision consolidation to occur is that the decision is interesting or involving (Benthorn, 1994; Festinger, 1964; Svenson et al., 1994). Degree of involvement seems to be directly related to degree of consolidation (Svenson, et al., 1994; Festinger, 1964; Janis \& Mann, 1977). Involvement and importance of a decision can be influenced in different ways. If the domain of the decision problem is not engaging, or if it is not important to the self, there is less need for restructuring. (Svenson \& Malmsten, 1996; Svenson et al., 1994).

In addition to involvement, uncertainty may affect consolidation. If an individual is certain of one alternative over the other before the decision is made, then the alternatives will already in the pre-decision phase be spread sufficiently apart, leaving less need for post-decision consolidation (Svenson, 1996). Thus, there may be ceiling- and/or floor effects leaving no space for increasing spreading in the post-decision phase. An individual may be uncertain about what goals to elicit in a decision-situation and how the attractiveness of the alternatives relates to this goal (Svenson, 2003). To illustrate, an individual may be uncertain about how the alternatives of a prohibition against religious symbols in school or not, relate to his/her goal of being an unprejudiced person. On the one hand, a prohibition may lead to less discrimination, on the other hand, a prohibition may in itself be perceived a racist act. Thus, an issue as exemplified above should have an impact on both involvement and uncertainty, and may hence be subjected to influences from other circumstances connected to the decision. One such circumstance is the procedure that is used to reach a group decision 


\section{General aims and hypotheses}

The general aim of the present thesis is to better understand how individuals in a larger social group react to different decision-making forms. Based on three studies, the present thesis focuses on different aspects of such decisionmaking.

There are different ways for a group to reach a decision, by using different decision-making procedures or forms such as ingroup authority decisions, outgroup authority decisions, or a voting procedure. Such procedures have different impact on the individuals' social identity, and thus also for how they perceive others (Lind \& Tyler, 1988; Tyler et al., 1996; Tyler \& Blader, 2003).

In Study I, we investigated how individuals perceive others with whom they agree and disagree in a decision situation. In line with social identity theory and previous findings, we expected that individuals would differentiate between those who agreed with them and those who disagreed with them, such that the former group was perceived more positively (Kenworthy \& Miller, 2002; Reeder et al., 2005). Extending current research, we also investigated the role of decision-maker's group membership. According to social justice research, an ingroup authority decision has the most impact on self-relevant concerns, which in turn affects group-serving behaviors (Lind \& Tyler, 1998; Tyler \& Lind, 1992). Hence, it was hypothesized that individuals would display strongest intergroup biases, when the decision was made by an ingroup authority. In the second experiment this notion was further extended by adding another social identity dimension, that of subgroup identification. Because importance may be interpreted as a proxy for identification (Reeder et al., 2005), we expected the general intergroup bias to be magnified among those who found the issue to be important.

In the second study, we looked at how position towards the status quo could affect perceptions of allies and opponents, and whether numerical status affected such perceptions. Earlier research on system justification theory, and the status quo bias, suggests that defenders of the status quo may be more motivated to defend the status quo than challengers would be in trying to change it (Jost et al., 2004; Schweitzer, 1994). However, it has also been argued that challengers may feel exposed, which could elicit a need to justify and defend own position (O'Brien \& Crandall, 2005; De Dreu et al., 2008). One way to do so is by enhancing evaluations of one's allies and undermining the arguments of the opponents (O'Brien \& Crandall, 2005). 
Hence, this study aims to develop existing theory in the field of system justification and status quo bias, by adding an underinvestigated dimension, that is, the challengers' perspective. In addition, we wanted to rule out the possible confounder of perceived numerical status, which has been shown to affect such intergroup perceptions (Kenworthy \& Miller, 2002).

Finally, in Study III we examined the cognitive attractiveness restructuring from a pre- to a post-decision phase, and whether this differed between different decision-making forms. The main objective of this study was to investigate if individuals restructure a group decision in a similar fashion as has previously been found among individual decision-making. We expected that they would, and also that they would consolidate most in an ingroup authority decision. Again, this was based on social justice research, showing that in such cases, individuals are informed about self-relevance (Lind \& Tyler, 1998; Tyler \& Lind, 1992). We expected that such information may serve as a proxy for involvement in the issue, which decision research suggest increase consolidation (Benthorn, 1994; Festinger, 1964; Svenson et al., 1994). Thus, this last study aimed at integrating social identity theory, and social justice research with individual decision research. 


\section{Overview of studies}

\section{Study I: Biased attributions regarding the origins of preferences in a group decision situation}

"We rarely think people have good sense unless they agree with us" (Francois de La Rochefoucauld, Maxime, 1678).

\section{Background and objectives}

Ingroup favoritism is the tendency to present the groups to which an individual is affiliated in a positive light (Allport, 1954; Brewer, 2007). This is achieved by attributing positive characteristics to actions by ingroup members. Kenworthy and Miller (2002) argue that attitudes, when expressed, are themselves social behaviors that need to be explained. Because explanations of attitude bases differ in their social desirability, a foundation for biased attributions is created. For instance, a rational base for an attitude is more socially desirable than an external base. To the extent that a given attitude constitutes a part of an individual's identity, the attitude is also a criterion for group inclusion. Hence, group boundaries may be constituted by attitude position on an issue. By attributing positive motives to the attitudes of those who agree with the individual, the ingroup members, the ingroup is favorized.

Kenworthy and Miller (2002) found that individuals tend to ascribe more external reasons, such as group pressure, and less rationality to disagreeing others (outgroup), and less externality and more rationality to agreeing others (ingroup). Whereas their study established the existence of such attributional biases between opposing attitude positions, the main objective in the present study was to investigate how such biases may vary with decision procedures in a group decision.

We expected participants in an ingroup as compared to outgroup authority condition to display stronger biases regarding the origins of decision preferences of others who agree and disagree with the participant. This prediction was based on procedural justice research showing that ingroup authority 
treatment has implications for social identity (Huo, Smith, Tyler, \& Lind, 1996; Tyler, Degoey, \& Smith, 1996). Third-party authority decisions were compared to a participatory condition (ballot voting).

In addition, we expected a discordant decision outcome to increase biases, because it could be interpreted as a threat to personal and collective interests and signal the incorrectness of own attitude.

Finally, if individuals perceive an issue to be important, attributional biases seem to increase (Reeder et al., 2005). Hence we expected the effect of decision procedure and decision outcome to be moderated by issue importance. In the second experiment we explored decisions made by a third-party decision organ that was constituted of representatives from different subgroups, varying the proportion of own subgroup representatives.

\section{Experiment 1}

Four hundred high school students (178 males) participated in a questionnaire study on decision-making in school (mean age: 17.3 years, $S D=0.8$, range 15-20 years). Participants were presented with a hypothetical scenario in which they were to state their preferred alternative in the proposal of prohibiting religious symbols in school, or not. The independent variables were target group (agree/disagree with participant), which were measured within participants, decision-making procedure (ingroup authority, $n=132$ /outgroup authority, $n=125$ /majority, $n=143$ ), and decision-outcome (concordant /discordant with participant's preference), which were measured between participants. About half $(48.8 \%)$ of participants received a concordant outcome. Issue importance was also measured. The dependent variable for assessing biases was created by subtracting ratings of those who agreed from those who disagreed, for both externality and rationality, creating two difference indices.

\section{Results and discussion}

Two separate hierarchical regression analyses were conducted, using the difference indices for externality and rationality ratings as dependent variables regressed on a constant (1) in order to establish target group effects. An intercept different from zero indicates differentiation. In the second step, issue importance, decision-making form (dummy coded using majority decision as reference category), and decision outcome (dummy coded using discordant outcome as reference category) was entered. Two- and three-way interaction terms were entered in step 3 and 4, respectively.

For both rationality and externality, target group effects were established; participants rated agreers as more rational and less external than disagreers. For rationality, three predictors in step 2 turned out significant. Biases were stronger in the ingroup authority condition as compared to the outgroup authority condition, when outcome concorded, and when issue 
importance was high. The model was refitted using majority decision as reference category, showing that biases were stronger in ingroup decisions as compared to the majority, but that outgroup decisions did not differ significantly from majority decisions.

Regarding the externality dimension, biases increased with ingroup decisions (compared to outgroup decisions), a concordant outcome, and with increased issue importance. Again, the model was refitted using majority decision as reference category showing that ingroup decisions differed from majority decisions, but that outgroup decisions did not. No interaction effects were found on either dimension.

In sum, individuals tend to rate those who agree with themselves more favorably than those who disagree with oneself, confirming the presence of similar biases as previously found (Kenworthy \& Miller, 2002), and reflecting the tendency of naïve realism (Ross \& Ward, 1996). Possibly, biases increased in ingroup authority decisions because of the self-relevant implications brought along with this procedure (Tyler \& Blader, 2003). Further, issue importance increased biases, possibly because of higher identification with the ingroup constituted of those who agree with oneself (Reeder et al., 2005). Unexpectedly, biases increased when outcome concorded as opposed to discorded. This may be because of the sensitive nature of the issue of religious symbols. Participants may then have used outcome information to determine the "correct" preference. A concordant outcome may then function as false consensus increasing the belief of the objectivity of the preferred alternative (Festinger, 1954; Kelley, 1967).

\section{Experiment 2}

In the second experiment we chose to further investigate aspects of representative decision-making. Representatives from different subgroups may jointly decide for a group, as when political party representatives make governmental decisions. Such subgroups may differ in size according to numerical status (majority/minority). The numerical majority usually has most influence over the decision outcome. Hence, when an individual's own representatives are in majority they should have more influence over the decision outcome. Further, when own representatives decide, individuals become more biased. Thus, we expected that when an individual's own subgroup was in majority indicating that own representatives will decide, biases should be stronger compared to when they are in the minority. Also, we hypothesized that the effect of own subgroup size on biases would be magnified for those high, as opposed to low, in issue importance. Participants were 164 high school students (105 males, mean age: 17.7 years, $S D=0.9$, range 15-21 years). They were presented with a scenario describing that the students' council of their own school and an adjacent school were to make a joint decision on the religious symbols issue. Dependent variables were rationality and externality ratings of agreers and disagreers, measured within 
participants. Independent variables were issue importance, measured as in Experiment 1, proportion of ingroup representatives (minority, $n=$ 51/majority, $n=58$ /equal, $n=55$ ) relative to outgroup representatives, and decision outcome (concordant/discordant). Again, about half $(48.5 \%)$ of participants received a concordant outcome. Proportion and outcome were measured between participants. Difference indices of in- and outgroup ratings were computed as in Experiment 1.

\section{Results and discussion}

As in Experiment 1, the difference indices for rationality and externality ratings were created and regressed, in two separate hierarchical regression analyses, one for each dimension, on a constant (1) in the first step. Issue importance, proportion of ingroup representatives (dummy coded using equal as reference category), and decision outcome (using discordant as reference) were entered in step 2, and two-and three-way interactions were entered in steps 3 and 4, respectively. Target group results mirrored those found in Study 1, that is more externality and less rationality was ascribed disagreers, and more rationality and less externality was ascribed agreers, as did issue importance. Increased importance related to increased biases for the rationality dimension. Neither proportion of own subgroup representatives (majority/minority compared to equal) nor decision outcome reached significance as independent predictors. However, on the externality dimension, an interaction between own subgroup size (when own representatives were in majority as compared to when both subgroups were equal in size) and issue importance was found.

Simple slope analyses confirmed that those who were high, as compared to low, in importance ratings were more biased when own subgroup was in the majority. There were no effects of issue importance within the other two subgroup conditions (own representatives in minority, or subgroups equal in size). This can be seen in Figure 3. 


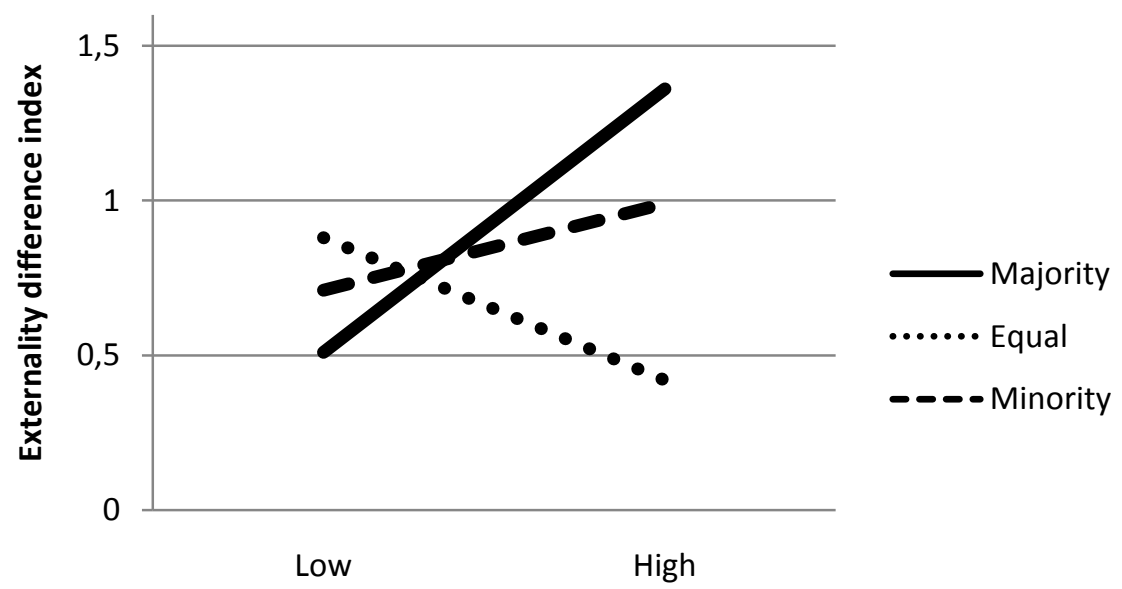

Issue importance

Figure 3. Predicted values for participants low and high in issue importance for the three subgroup sizes. The difference index has been reverse coded for easier interpretation. Higher values on the externality difference index imply more differentiation between in- and outgroup ratings.

\section{Conclusions}

Attributional biases regarding the origins of preferences seem to vary with different decision-making forms, and are strongest when own group representatives decide for the group and when the issue to be decided upon is perceived as important. In addition biases seem to exist between factions within a larger group. When own sub-group is in majority and the issue is important individuals become more biased than when the issue is not perceived as important. 


\title{
Study II: Defending or challenging the status quo: Position effects on biased intergroup perceptions
}

\begin{abstract}
"Great spirits have always found violent opposition from mediocrities. The latter cannot understand it when a man does not thoughtlessly submit to hereditary prejudices but honestly and courageously uses his intelligence." (Albert Einstein)
\end{abstract}

\section{Background and objectives}

Research indicates that individuals in general are status quo defenders, preferring to keep the current state of affairs as they are (Skitka et al., 2002; Jost et al., 2004). One way to undermine the arguments of challengers is to accuse them of being selfish (O'Brien \& Crandall, 2005). Individuals also tend to undermine the arguments of those with whom one disagrees (Ross \& Ward, 1996) and to enhance favorable evaluations of one's own ingroup (Tajfel \& Turner, 1979; Brewer, 2007).

As it has previously been shown that observers tend to perceive challengers of the status quo in a more negative light than defenders (Crandall et al., 2009; O'Brien \& Crandall, 2005), we wanted to extend this by using a firstperson perspective, where participants judge those with whom they agree (the ingroup) and disagree (the outgroup) on the rationality and externality bases of their attitude positions. We hypothesized that individuals in general are ingroup favorising, attributing more positive bases for attitudes of their ingroup and more negative bases for attitudes of their outgroup, which has been shown earlier (Kenworthy \& Miller, 2002; Reeder et al, 2005). Because challengers of the status quo are in a vulnerable and exposed position (De Dreu et al., 2008), where they are at risk for being criticized, we tentatively predicted that challengers would show more intergroup biases than defenders. Defenders should not feel that they are exposed to such a risk, and thus not be in any need to justify own position.

\section{Experiment 1}

Participants were 311 high school students (143 males) from the larger Stockholm area (mean age: $17, S D=0.8$, range 16-20 years). Participants were presented with a vignette on the issue of confiscation of cell phones by the teachers. The issue was described as a new policy suggestion that the school should decide upon. Participants stated own position on the new policy suggestion and, following some unrelated items, rated the rationality and externality of those who agreed and disagreed with own position. At the 
moment of the study, teachers were not allowed to confiscate cell phones, hence those who chose to oppose the new policy suggestion were categorized as defenders of the status quo, whereas those who supported the suggestion were categorized as challengers of the status quo. The independent variable was position towards the status quo (defender/challenger), which was measured between participants, and the dependent variable was target group (ingroup/outgroup) ratings on rationality and externality, measured within participants. Thus, this study extends previous findings in Study 1, by adding the position variable. In total, 208 participants were defenders, and 100 challengers. Three participants, who did not state own position, were excluded.

\section{Results and discussion}

Two repeated measures ANOVA's (one for each dimension) showed significant main effects indicating that individuals in general show ingroup favoritism rating the ingroup (agreers) as more rational and less externally influenced and the outgroup (disagreers) the other way around. There was also a significant interaction with position towards the status quo showing that challengers displayed stronger intergroup biases than did defenders, on both dimensions. We argue that this asymmetry is due to challengers' exposed position, giving rise to an increased need to defend and justify own position. Hence, being in the challenging position could be interpreted as a social threat.

It has previously been shown that being in the minority may be perceived as a social threat eliciting biases. In light of being a challenger or defender of the status quo it is possible that challengers, who defy the current order, also would perceive themselves as belonging to the minority. Hence it is possible that the effects we found of position towards the status quo are actually driven by perceptions of numerical status.

\section{Experiment 2}

As Kenworthy and Miller (2002) have shown, being informed that own party is in minority poses a threat to social identity increasing intergroup differentiation, numerical status was controlled for in Experiment 2. Further extending the results in Experiment 1, we added two additional issues. Participants were 135 undergraduate students (42 males) at Stockholm University (mean age: $28, S D=11.4)$. Participants were randomly assigned to one of three issue conditions; the cell phone issue $(n=44)$, if religious symbols should be prohibited in school $(n=45)$, or if gay couples should be allowed to adopt children from foreign countries $(n=46)$. At the time of the data collection the status quo was that teachers were not allowed to confiscate cell phones, religious symbols were not prohibited, and gay couples were not allowed adoption. Participants stated own preferred alternative. Participants read a 
short passus stating that the researchers had done a previous study on this issue. One third in each issue was informed that in the previous study it was found that there was a large majority against the proposition, one third was informed that there was a large majority in favor of the proposition, and one third was not given any numerical information. This manipulation was adapted from Kenworthy and Miller (2002). Then participants rated the rationality and externality of their in- and outgroup. Hence, the independent variables were issue (cell phones/religious symbols/gay couples), and numerical status information (majority against/majority in favor/no numerical information), which were measured between participants. The dependent variables were ratings of externality and rationality for the target groups (ingroup/outgroup), which was measured within participants. We did not expect differences between issues.

\section{Results and discussion}

A univariate ANOVA showed that there were no differences in biases across issues, hence all issues were collapsed and analyzed together. There was a main effect of target group, such that the ingroup was rated as more rational and less externally influenced, whereas the outgroup was rated as less rational and more externally influenced. Two repeated measures ANOVA's, one for each dimension, revealed that position significantly affected biases as in Experiment 1; challengers of the status quo showed stronger intergroup biases than did defenders. Neither a main effect of numerical status nor an interaction between position and numerical status was found.

The finding that challengers were more biased, regardless of being in the majority or minority seems to suggest that the possible social identity threat posed by position is stronger than that from numerical status. Possibly, knowing that one is challenging what is generally known to be the good and true, and actively doing so, may have more profound impact on the individual than belonging to the numerical minority.

\section{Conclusions}

When individuals challenge the status quo they become more biased and have less tolerance for disagreeing others. This effect is independent and overriding effects of numerical status. Hence, the challenging position per se seems to elicit attributional biases. 


\title{
Study III: Post-decision consolidation in large group decision-making
}

\begin{abstract}
"Do not be afraid of the past. If people tell you that it is irrevocable, do not believe them." (Oscar Wilde)
\end{abstract}

\section{Background and objectives}

As most studies regarding decision-making have focused on the cognitive processes taking place prior to a decision within a sole decision-maker (Payne, Bettman \& Johnsson, 1992; Russo \& Carlson, 2002), the objective of this study was to turn focus to the individual's cognitive post-decision processes when in a group decision. Building on early theories of cognitive dissonance (Festinger, 1957; 1964; Janis \& Mann, 1977), the present study concerns attractiveness restructuring of specific attributes of a preferred and non-preferred alternative, such that the preferred alternative becomes superior from a pre- to a post-decision phase; a process called consolidation (Svenson, 1992).

Based on the models of procedural justice, two decision-making forms were explored; ingroup authority decisions and outgroup authority decisions. Since individuals become more involved when a decision is made by ingroup authorities (Tyler, 1994, 2004; Ståhl et al., 2004), and involvement increases consolidation (Svenson, 1992), it was hypothesized that individual consolidation would be stronger when ingroup authorities had decided for the group. In addition, it has previously been shown in decisions in threeperson groups that a decision outcome discordant with the individual's own preference increased consolidation (Hammarberg \& Svenson, 2000). Thus, we predicted that a discordant outcome in the present situation where the decision concerned a larger group would also lead individuals to consolidate more, than if the outcome was consistent with their preferred alternative.

In Experiment 1, the issue that the group was to decide upon was whether teachers should be allowed to confiscate students' cell phones, in cases where they disturbed the class, or not. In the second experiment, we wanted to extend the first experiment by using another issue; whether students should be prohibited from wearing religious symbols in school (e. g. veil, necklace with crucifix) or not. In addition, we added another decision condition where a majority decision was reached after a ballot voting procedure. Finally, we measured school identification, because those identifying more with the group should be most influenced by the decision procedures and hence consolidate more. 


\section{Experiment 1}

Participants in Experiment 1 were 175 Swedish high school students (91 males) from the larger Stockholm area (mean age: 16.9, $S D=0.8$, range 1620 years). The independent variables were decision-making form (ingroup decision-maker/outgroup decision-maker), and decision outcome (concordant/discordant with own preference). Decision-making forms (ingroup decision-maker, $n=86 /$ outgroup decision-maker, $n=89$ ), and outcome (prohibition/no prohibition) conditions were randomly assigned. This resulted in $57 \%$ of participants receiving a concordant outcome. The dependent variables were consolidation effects on the three most important attributes, here labeled values, of the decision alternatives, chosen by the participant.

The questionnaires were distributed in the participant's school during class hours. It began with a description of the issue of confiscation of disturbing cell phones. Then they were asked to imagine that a decision on the issue was to be made at their school. They chose three attributes out of a list of nine. The attributes were presented as important values to consider when deciding what alternative to prefer. For instance a value may be "to create a good learning environment". Participants rated the attractiveness of both alternatives (to allow confiscation/to not allow confiscation) with respect to the value at hand. This was done for the three most important values that they had chosen themselves. After this, they stated their own preferred alternative and answered some unrelated items. This constituted the first questionnaire, and when finished, the participants put it away and started on a second questionnaire.

In the second questionnaire, participants were informed that the decision at their school was done either by ingroup authorities (student's council) or outgroup authorities (principal and teachers), and the outcome (prohibition/no prohibition). After this information, participants again rated the attractiveness of the same attributes as before along with further unrelated items.

To calculate consolidation, the difference between the ratings of the preferred and non-preferred alternative at time 1 (pre-decision differentiation) was subtracted from the difference between the preferred and non-preferred alternative at time 2 (post-decision differentiation), for each attribute. If the difference is positive, consolidation has occurred.

\section{Results and discussion}

Consolidation effects were found on the most important attribute indicating that individual members in large group decisions consolidate their own preferred alternative similarly as has been found in individual decision-making. There were no significant effects on the second and third most important attributes, which is not uncommon (Svenson, 2006). In line with our hypothesis, consolidation effects were stronger when ingroup authorities made 
the decision as opposed to when outgroup authorities decided. This result is interpreted as increased involvement in ingroup authority decision-making due to the self-relevant information transmitted to group members in this decision form, as opposed to outgroup authority decisions. Hence, the result is in line with expectation from procedural justice research (Smith et al., 1998; Tyler \& Blader, 2003).

There was also a tendency for participants getting a discordant outcome to consolidate more than those getting a concordant outcome, which was in line with expectations.

In a second experiment we extended the first by using a different decision issue, adding a third decision form, and measuring identification with the school.

\section{Experiment 2}

A highly controversial issue that has been debated across many European countries, including Sweden, is whether students should be prohibited from wearing religious symbols in school, or not. Hence, in this experiment we used this issue.

Participants were 322 high school students (139 males) from the larger Stockholm area (mean age: $17.3, S D=0.8$, range $15-19$ years). In addition to the previously used decision-making forms, a majority decision (ballot voting) was added. We expected that participants in this condition would show similar consolidation effects as in an ingroup authority condition. That is, participants in the majority condition should consolidate more than participants in the outgroup authority condition. This hypothesis was based on the procedural justice premise that not only treatment from authorities convey important self-information but also treatment from other group members (Tyler \& Blader, 2003). Hence, ingroup members should be the primary factor eliciting consolidation also in a non-hierarchical decision. In addition, participants' identification with their school was measured, with the hypothesis that participants who strongly identify with their school also should be most influenced by decision procedures. Thus, we expected that consolidation would be strongest when ingroup members decided and the individual strongly identified with the school.

The independent variables were decision-making form (ingroup decision-maker, $n=104 /$ outgroup decision-maker, $n=105 /$ majority decision, $n$ = 108), decision outcome (concordant/discordant with own preference), and identification with the school, as measured by four items adapted from Smith and colleagues (1998). Fifty-two percent of participants received a concordant outcome. The dependent variables were again consolidation effects on the three most important attributes chosen by the participant. The procedure followed those of Experiment 1. 


\section{Results and discussion}

Three separate hierarchical regression analyses, one for each attribute, revealed consolidation effects on the most important attribute, but not the second or third most important attribute, in line with results from Experiment 1 . On the most important attribute there was a significant main effect of identification, such that participants identifying more with the school also consolidated more. There were no main effects of either decision-form or decision outcome. However there was a significant interaction between identification and decision-making form. Simple slope analyses revealed high identifiers in both ingroup decision forms (ingroup authority and majority), consolidated significantly more than did high identifiers in the outgroup authority condition. No differences were found for low identifiers between the decision conditions. The interaction is shown in Figure 4 below.

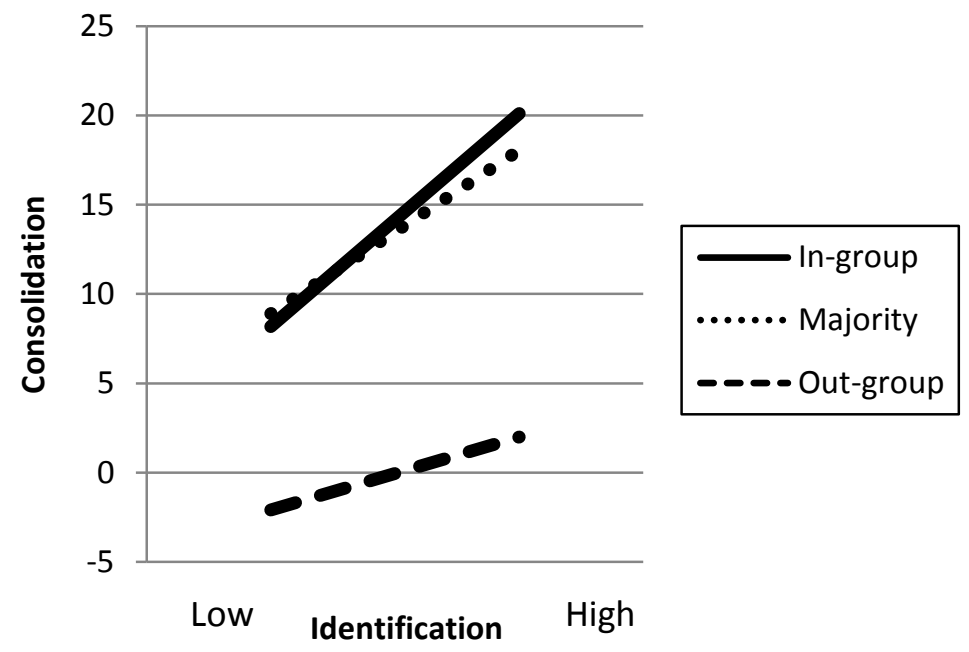

Figure 4. Predicted consolidation values for participants low and high in school identification in the three decision form conditions.

\section{Conclusions}

Individuals in a large group decision bolster their own preferred alternative by consolidation similarly to what has previously been found in individual decision-making. This effect is particularly prominent when ingroup members have made the decision, regardless of the hierarchical status of those members. Further, high identification with the social group magnifies the effects of decision condition, such that high identifiers consolidate more when ingroup members decide as compared to outgroup members. 


\section{General discussion}

The main objectives of the present thesis were to investigate how group membership in large group decisions affects intergroup biases, and to investigate individual cognitive restructuring of the group decision. Secondly, I wanted to study how attitude position towards a possible new policy suggestion, that is, the status quo, would affect intergroup perceptions. Overall, the results showed that individuals in large group decisions perceive others, who do not agree with them as less rational and more influenced by external factors. These effects were magnified when ingroup authorities made the decision. In addition, such intergroup biases seem stronger among challengers of the status quo than among defenders. Further, individuals in large group decisions cognitively restructure a decision similarly to what has been shown on an individual level, and that restructuring was strongest when own group representatives decided. The results are important as they reveal how individuals perceive others in their social group, and ultimately for their tolerance of others' perspectives, the possibilities to reach common agreements, and development and implementation of new policies.

\section{Main findings}

To belong to different social groups constitute important parts of the individual's social identities (Tajfel \& Turner, 1979; Brewer, 2007). Within social justice research it has been shown that when an individual identifies more with a social group, they also care more about the procedures used when the group is going to make a decision that will affect all of the group's members (Huo, 2003; Huo et al., 1996; Platow, Wenzel, \& Nolan, 2003; Smith et al., 1998). Because fair procedures carry information about an individual member's respect and position in the group, members tend to become more involved when procedures are fair (Tyler \& Blader, 2003). When ingroup authorities make decisions, fair procedures are of extra importance (van Knippenberg, de Cremer, \& van Knippenberg, 2007). Because fair procedures carry identity relevant information, ingroup authority decisionmaking may also constitute a threat to own identity. Because threat has been shown to increase intergroup attributional biases (Branscombe \& Wann, 1994; Kenworthy \& Miller, 2002; Stephan et al., 2002), we expected attributional biases regarding the origins of preferences to vary with decision- 
making form as well. In Study 1, it was confirmed that when own group representatives decided for the group, members became more biased towards others with opposing preference position. In line with earlier findings (Reeder et al., 2005), this asymmetry was magnified among those who perceived the issue to be important. If an individual perceives an issue as important, preferences should be stronger, and those individuals should identify more with the group. In line with social identity theory, intergroup differentiation should be greatest among those highly identified with the group (Hogg, 2006; Tajfel \& Turner, 1979).

When group boundaries are composed of preference position towards a new policy, position towards the status quo should also affect individual's perceptions of others. Because being on the challenging side implies social threats and social costs as being criticized for challenging the generally perceived good and true status quo, we expected challengers of the status quo to be more biased in their perceptions of disagreeing others than defenders would be. This was established in Study 2, which also showed that position is more important for such biases than numerical status. This article fills a gap in previous research that has mostly focused on how individuals perceive others challenging or defending the status quo, without concern for the participant's own position, or used issues that are of less relevance to the participant. This idea, that there is a social cost of challenging is only hypothetical, and is an objective for my future research.

Because involvement differs across different forms of reaching a decision, it was expected that individual decision consolidation of own preferred alternative would differ accordingly, and be strongest when involvement is strongest; that is, when ingroup authorities decide. It was shown in Study 3 that members of a large group cognitively restructured the attractiveness of two alternatives in favor of their own preferred alternative in a group decision similarly to what has previously been found for individual decisionmaking. In addition, such consolidation effects were pronounced when own group representatives had decided for the group, supporting our hypotheses.

In sum, the present thesis provides important insights into the minds of members of organizations or other social groups, when common decisions regarding new policies are to be made. Because such decisions are part of everyday life on different levels of group membership ranging from small work groups, recreational groups to the democratic system, the insights from the present thesis are central for further understanding the tolerance and recognition of others' opinions, for the success in reaching common goals, for the acceptance of common decisions, and ultimately for the psychological well-being and peaceful relations between individuals. 


\section{Outcome effects}

Because an outcome discordant with an individual's own preference might be interpreted as a threat to personal and collective interests, we hypothesized that both consolidation and intergroup biases should increase when the decision outcome discorded with participants' own preference. In Study 3, outcome effects on consolidation tended to be in the expected direction, although not significantly so. We argue that the large group context may explain the lack of significance. Because individuals in large groups are more anonymous than they are in smaller groups, the need to protect own preference may not be as strong in this situation. In Study 1, however, we found significant effects of decision outcome in the first experiment, but in a direction opposite to the expected. That is, participants getting a concordant outcome showed higher levels of intergroup biases, than those getting a discordant outcome. Several explanations for these results can be discussed, but leaves open the question of why results differed between the two studies. In the following section, I will provide explanations of this difference.

First, because a concordant outcome may imply correctness of own preference, participants may have used outcome as a source to what other participants prefer, and thus believed that others to a larger extent share own position when outcome concorded. If individuals believe that consensus is high, they also believe that their viewpoint is the objectively correct (Kelley, 1967). When it comes to the issue of prohibiting religious symbols, which was the issue used in both experiments in Study 1, participants may have had more difficulty in deciding upon their own position, than in the cell phone issue (used in Experiment 1 in Study 3). Both prohibition and no prohibition could be interpreted as non-racial, pro-social positions. This issue is highly sensitive in the respect that individuals are very attentive not to signal racist attitudes. Thus, in such a difficult situation a validating outcome may result in relief and increased certainty that own position is the correct one from a social desirability perspective. That implies that those who disagree represent a position that is undesirable and incorrect, thus the explanation of their preference becomes less favorable. This interpretation is supported by the overall weaker effects in Experiment 1, the cell phone issue, compared to Experiment 2, the religious symbols issue, in Study 3. Our high school participants probably were more confident when deciding on the cell phone issue, as position in this issue does not carry such a sensitive message.

Second, it is important not to draw too large generalizations from outcome results in Study 1, as the statistical significance of the first experiment was not replicated in the second experiment, complicating the interpretation of how a concordant or discordant outcome actually affect individuals.

Third, consolidation and biased attributions, although possibly connected, do not measure the same thing. It is possible that a discordant outcome increases consolidation because individuals engage themselves more cogni- 
tively in the issue and become even more uncertain than they were before, and at the same time they may become more biased in their perceptions of others getting a concordant outcome, feeling relieved. Thus, a discordant outcome may induce uncertainty, which should lead to less bias. If an individual perceives that the opposing party's position may be as valid as his/her own, then it should be difficult to attribute negative reasons for the opposition and positive reasons for the ingroup. If individuals become extremely uncertain about own position, group boundaries composed of attitude position may even no longer be valid. However, this reasoning is purely hypothetical and should be further explored in future research.

Finally, because procedures are more important than outcome according to the group engagement model (Tyler \& Blader, 2003), the fact that only one out of a total of four experiments yielded significant outcome effects may reflect the primacy of procedural concerns over distributive concerns when it comes to intergroup biased attributions and decision consolidation. It is important to note here that procedural justice measures how fair the procedure was, not how fair the outcome is perceived. It is possible that participants may have perceived the outcome of a fair decision process as unfair. In addition, the significant effects that were found, increased group-serving attributions when the outcome concorded, which is actually in line with predictions from the group engagement model. It states that outcome favorability may increase identification with the group, and thus also group-serving behaviors (Tyler \& Blader, 2003).

\section{Status quo effects}

In relation to the results found in Study 2, that challengers of the status quo were more biased than defenders, it is necessary to discuss some previously presented explanations to why defenders should be more biased, and to discuss a possible next step for this research.

\section{Loss aversion}

Loss aversion is the tendency individuals have to avoid losses. Avoiding losses are psychologically a stronger motivation than is the motivation to achieve gains of equal magnitude (Kahneman \& Tversky, 1979). Loss aversion has been used to explain the status quo bias (Schweitzer, 1994). However, it has recently been shown that perceiving oneself as being a powerful person reduces loss aversion (Inesi, 2010). De Dreu and colleagues (2008) have shown that defenders of the status quo perceived themselves as more powerful than did challengers of the status quo. Hence, it is possible that defenders of the status quo will not engage in such group differentiation. Power has traditionally been linked to increased biases (Fiske, 1993). Perhaps in a situation where loss aversion may be present, as is the case when assessing position towards the status quo, the effects of power and reduced 
loss aversion biasing judgments in different directions may cancel each other out, resulting in less strong intergroup biases. This reasoning, however, is purely hypothetical, and an empirical issue to be addressed in future studies.

\section{Perceived control}

Another possible explanation to the results from Study 2 has to do with the feeling that as a challenger, one lacks control over the situation (De Dreu et al., 2008). A lack of control is also found among socially excluded individuals (Williams, 2007). Previous research on social exclusion indicates that feeling excluded is highly similar to feeling socially threatened and responses fall in the same categories (Williams, 2007). After being excluded, participants may display intergroup differentiation (Williams, 2007), which was also found when individuals are socially threatened in other ways (Kenworthy \& Miller, 2002). Hence, exclusion, social threat, and challenging the status quo are all related to decreased feelings of control. Feeling that one is not in control may be the underlying mechanism driving intergroup differentiation, and the link between being in the challenging position and experiences of social exclusion should be investigated in future studies.

\section{Methodological comments}

\section{The scenario design}

Both the first and the second study are based on scenarios describing a situation to the participant where a decision on an important issue is to be made at their school. The different forms of making a decision at a large group level are then mentioned. This information was provided to the participants in the first questionnaire. In the second questionnaire they were asked to imagine that the decision had been made, and depending on the decision condition, more detailed information about how the decision had been reached was provided. These situations are of course quite artificial, and thus we do not know whether all participants were actually able to realistically engage themselves in the descriptions. Such a design, utilizing scenarios, should lower the probability to find significant effects, because it may not be perceived as realistic. The simple fact that we actually did find significant effects, however, seems to indicate that at least the majority of our participants managed to engage themselves in the scenarios described to them. However, it is still necessary to be cautious when generalizing the results to underlying causal mechanisms and real world occurrences. In order to validate the findings, a study using real, rather than hypothetical decisions should be carried out. 


\section{The emotionality dimension}

The original dimensions for explaining the attitudes of other individuals included, beside rationality and externality, an emotionality dimension. That is, to hold an attitude because it feels good. This dimension was omitted from the studies included in the present thesis. Kenworthy and Miller (2002) established in a pilot study that it was indeed perceived less desirable to hold an attitude because of emotional reasons as compared to rational reasons. Hence, ascribed emotionality should be interpreted as a negative evaluation of others, which was found in the first experiment, where participants ascribed more emotionality to the outgroup than to the ingroup. However, neither in their Experiment 2 or 3, did the emotionality dimension yield significant differences between target groups or the expected interactions with social threat. The authors conclude that "the data for this attributional dimension were not particularly compelling in either Study 2 or Study 3" (p. 703). Thus, the evaluative implications of this dimension are still unclear and may differ according to situation (i. e. characteristics of the issue at hand). Because of this, we decided not to include the emotionality dimension at all.

\section{Theoretical comments}

\section{The externality dimension}

Ingroups are psychologically primary in the sense that liking and positive affect to an individual's ingroup(s) come prior to the formation of attitudes towards any outgroups (Allport, 1954, p. 42; Brewer, 2007). This implies that ingroup bias and ingroup favoritism does not necessarily need a comparative outgroup (Brewer, 2007; DiDonato, Ullrich, \& Krueger, 2011). To the extent that externality ratings imply outgroup negativity, the smaller effects on externality ratings could be explained by the notion that individuals are foremost concerned with creating a positive ingroup image, and outgroup negativity are less important.

Even though Kenworthy and Miller (2002) interpreted high externality ratings to the outgroup as outgroup negativity, they discuss an alternative interpretation. Attributions of externality may be utilized to keep a positive image of an outgroup member. If individuals are concerned with keeping a positive image of their outgroup, the outgroup's members may simply be victims of external forces. This is in line with naïve realism, describing that if others do not agree with the individual, they may be misinformed. If they are correctly informed they should sway to the same position as the individual him/herself advocate (Ross \& Ward, 1996). Such an explanation of externality ratings implies a social motivation to uphold social relationships. In the present thesis, we have chosen not to discuss this explanation, but rather chosen to employ the original interpretation by Kenworthy and Miller (2002). However, we do acknowledge that this interpretation may have va- 
lidity, especially in the scenarios used in our studies where opposing attitudes create group boundaries, but where factions are part of a larger social group, namely the school. The interpretation of the externality dimension should be investigated further in studies utilizing different levels of group affiliation where the social motivation to uphold relationships can be further explored.

\section{Implications}

\section{The downside of representative decision-making}

Representative decision-making is the norm of a democratic society. It is considered a fair procedure and has such positive effects as promoting a high degree of decision acceptance (Tyler, 1994), and a deeper decision problem elaboration in turn leading to better and more well-informed preferences (DeDreu, Nijstad, \& van Knippenberg, 2008). However, it may have disadvantages regarding how individuals perceive the decision alternatives and other people. In this situation, bolstering of own position increase, possibly leading to less consideration of new information and other perspectives, increasing polarization of preferences. This was also shown in Study 1, where participants became more biased and less tolerant of disagreeing others when ingroup members decided. Bolstering and biased intergroup perceptions are consequences that should be closely associated. Both of them should have a negative impact on the possibility of reaching a common ground of understanding. Further, as the negative perceptions of others seem to be associated with position towards the status quo, it is understandable that challengers of the status quo sometimes engage in what has been termed negative campaigning, such as smearing of the opponents, for example by

attributing mental defects to them (Felkner, 1992). The consequences of negative campaigning in terms of outcome success and tolerance for challengers have not been investigated and thus constitute an important next step.

\section{Suggestions for the future}

Although bringing some clarity to relations between opposing factions within a group in a decision situation, several questions arise from the present thesis that should be more closely investigated. Because of the hypothetical decision situations presented to the participants it is not entirely certain that the findings from the present studies are directly generalizable to real life. Therefore, first, the results from the scenario studies should be validated in a real life decision setting. In addition to the cognitive measures of intolerance for opposing others, behavioral measures of intolerance should be included; do negative attitudes transfer to actual behavior? Second, the implication of 
the externality dimension should be investigated more closely. Is there a valid ground for the argument that externality may in fact be used to uphold a positive image of the outgroup as a whole, or specific members of the outgroup? Third, the implications of receiving a concordant or discordant outcome should be explored. On the one hand we have argued that threat to personal and collective interests, as implied by a discordant outcome, should elicit intergroup differentiation. On the other hand, we have argued that outcome information may be utilized as a heuristic for the correctness of one's own preference position and that such a validation of own position may elicit intergroup differentiation. Fourth, regarding the third study, the above discussed loss aversion - power relationships deserve attention. Could it be that increased loss aversion and the feeling of being in power, both connected to being in the defending position, balance each other out resulting in less intergroup differentiation for defenders? Finally, as I have argued above, is the feeling of lacking control an underlying concept driving intergroup differentiation in both the challenging position and social exclusion? Importantly, do challengers feel social exclusion?

I would like to conclude this thesis with a quote by the Florentine writer and philosopher Niccolò Machiavelli (1469-1527), which I think nicely applies to all research; "I am not interested in preserving the status quo; I want to overthrow it". 


\section{References}

Alexander, S., \& Ruderman, M. (1987). The role of procedural and distributive justice in organizational behavior. Social Justice Research, 1, 177-198.

Allport, G. (1954). The nature of prejudice. Cambridge, MA: Addison-Wesley.

Baumeister, R. F., \& Leary, M. R. (1995). The need to belong: Desire for interpersonal attachments as a fundamental human motivation. Psychological Bulletin, $117,497-529$.

Benthorn, L. (1994). On post-decision processes. Lund University Doctoral dissertation, Lund: Sweden.

Benson, III, L. (1993). Studies in human decision making: On the effects of experimental instructions, framing and time constraints. Lund University Doctoral dissertation, Lund: Sweden.

Bettencourt, B. A., Miller, N., \& Hume, D. L. (1999). Effects of numerical representation within cooperative settings: Examining the role of salience in ingroup favouritism. British Journal of Social Psychology, 38, 265-287.

Biernat, M., \& Vescio, T. K. (1993). Categorizing and stereotyping: Effects of group context on memory and social judgment. Journal of Experimental Social Psychology, 29, 166-202.

Blader S. L., \& Tyler T. R. (2005). How can theories of organizational justice explain the effects of fairness? In J. Greenberg \& J. Colquitt (Eds.), Handbook of organizational justice (pp. 329-354). Mahwah, NJ: Erlbaum.

Branscombe, N. R., \& Wann, D. L. (1994). Collective self-esteem consequences of outgroup derogation when a valued social identity is on trial. European Journal of Social Psychology, 24, 641-657.

Brehm, J. W., \& Mann, M. (1977). Effects of importance of freedom and attraction to group members on influence produced by group pressure. Journal of Personality and Social Psychology, 31, 816-824.

Brewer, M. B. (1991). The social self - On being the same and different at the same time. Personality and Social Psychology Bulletin. 17, 475-482.

Brewer, M. B. (2001). Ingroup identification and intergroup conflict: When does ingroup love become outgroup hate? In R. Ashmore, L. Jussim, \& D. Wilder (Eds.), Social identity, intergroup conflict, and conflict reduction (pp. 17-41). New York: Oxford University Press.

Brewer, M. B. (2007a). The social psychology of intergroup relations: Social categorization, ingroup bias, and outgroup prejudice. In A. W. Kruglanski, \& E. T. Higgins (Eds.), Social psychology: Handbook of basic principles (pp. 695-715). New York: Guildford Press.

Brewer, M. B. (2007b). The importance of being we: Human nature and intergroup relations. American Psychologist, 62, 728-738. 
Brewer, M. B., \& Brown, R. J. (1998). Intergroup relations. In D. T. Gilbert, S. T. Fiske, \& L. Gardner (Eds.). The handbook of social psychology (4th ed., pp. 554-594). New York: McGraw-Hill.

Brockner, J., Tyler, T. R., \& Cooper-Schneider, R. (1992). The influence of prior commitment to an institution on reactions to perceived unfairness: The higher they are, the harder they fall. Administrative Science Quarterly, 37, 241-261.

Brownstein, A. L. (2003). Biased predecision processing. Psychological Bulletin, 129, 545-568.

Campbell, D. T. (1958). Common fate, similarity, and other indices of the status of aggregates of persons as social entities. Behavioral Science, 3, 14-25.

Chaiken, S., Pomerantz, E. E., \& Giner-Sorolla, R. (1995). Structural consistency and attitude strength. In R. E. Petty \& J. A. Krosnick (Eds.), Attitude strength: Antecedents and consequences (pp. 387-412). Hillsdale, NJ: Erlbaum.

Chua, H. F., Leu, J., \& Nisbett, R. E. (2005). Culture and diverging views of social events. Personality and Social Psychology Bulletin, 31, 925-934.

Conway, M., \& Ross, M. (1984). Getting what you want by revising what you had. Journal of Personality and Social Psychology, 47, 738-748.

Corneille, O., Yzerbyt, V. Y., Rogier, A., \& Buidin, G. (2001). Threat and the group attribution error: When threat elicits judgements of extremity and homogeneity. Personality and Social Psychology Bulletin, 27, 437-446.

Crocker, J., \& Luhtanen, R. (1990). Collective self-esteem and ingroup bias. Journal of Personality and Social Psychology, 58, 60-67.

De Dreu, C. K. W., Kluwer, E. S., \& Nauta, A. (2008). The structure and management of conflict: Fighting or defending the status quo. Group Processes and Intergroup Relations, 11, 331-353.

De Dreu, C. K. W., Nijstad, B. A. \& van Knippenberg, D. (2008). Motivated information processing in group judgment and decision making. Personality and Social Psychology Review, 12, 22-49.

DiDonato, T. E., Ullrich, J., \& Krueger, J. I. (2011). Social perception as induction and inference: An integrative model of intergroup differentiation, ingroup favoritism, and differential accuracy. Journal of Personality and Social Psychology, 100, 66-83.

Duck, J. M., \& Fielding, K. S. (2003). Leaders and their treatment of subgroups: Implications for evaluations of the leader and the superordinate group. European Journal of Social Psychology, 33, 387-401.

Eagly, A. H., \& Chaiken, S. (1998). Attitude structure and function. In D. T. Gilbert, S. T. Fiske, \& L. Gardner (Eds.). The Handbook of social psychology (4th ed. Vol 1, pp. 269-322). New York: McGraw-Hill.

Felkner, B. L. (1992). Political mischief: Smear, sabotage, and reform in U. S. elections. New York: Praeger.

Festinger, L. (1954). A theory of social comparison processes. Human Relations, 7, 117-140.

Festinger, L. (1957). A theory of cognitive dissonance. Stanford: Stanford University Press.

Festinger, L. (1964). Conflict, decision and dissonance. Stanford: Stanford University Press.

Fiske, S. T. (1993). Controlling other people - the impact of power on stereotyping. American Psychologist, 48, 621-628. 
Fiske, S. T. (2004). What's in a category?: Responsibility, intent, and the avoidability of bias against outgroups. In A. G. Miller (Ed.). The social psychology of good and evil (pp. 127-140). New York: Guildford Press.

Fiske, S. T., \& Taylor, S. E. (2008). Social cognition: From brains to culture. New York: McGraw-Hill.

Gilbert, D. T., Pelham, B. W., \& Krull, D. S. (1988). On cognitive busyness: When person perceivers meet persons perceived. Journal of Personality and Social Psychology, 54, 733-739.

Hamilton, D. L., \& Sherman, S. J. (1996). Perceiving persons and groups. Psychological Review, 103, 336-355.

Hammarberg, A., \& Svenson, O. (2000). Individual postdecision processes in group settings. Scandinavian Journal of Psychology, 41, 145-158.

Heider, F. (1946). Attitudes and cognitive organization. Journal of Psychology: Interdisciplinary and Applied, 21, 107-112.

Heider, F. (1958). The psychology of interpersonal relations. New York: Wiley.

Hogg, M. A. (2006). Uncertainty-identity theory. Advances in Experimental Social Psychology, 39, 69-126.

Hogg, M. A., \& Abrams, D. (1988). Social identifications: A social psychology of intergroup relations and group processes. London: Routledge.

Hogg, M. A., Hohman, Z. P., \& Rivera, J. E. (2008). Why do people join groups? Three motivational accounts from social psychology. Social \& Personality Psychology Compass, 2, 1269-1280.

Hogg, M. A., \& Turner, J. C. (1987). Intergroup behaviour, self-stereotyping, and the salience of social categories. British Journal of Social Psychology, 26, 325340 .

Huskinson, T. L. H., \& Haddock, G. (2004). Individual differences in attitude structure: Variance in the chronic reliance on affective and cognitive information. Journal of Experimental Social Psychology, 40, 82-90.

Huo, Y. J. (2003). Procedural justice and social regulation across group boundaries: Does subgroup identity undermine relationship-based governance. Personality and Social Psychology Bulletin, 29, 336-348.

Huo, Y. J., Smith, H. J., Tyler, T. R., \& Lind, E. A. (1996). Superordinate identification, subgroup identification, and justice concerns: Is separatism the problem; is assimilation the answer? Psychological Science, 7, 40-45.

Inesi, M. E. (2010). Power and loss aversion. Organizational Behavior and Human Decision Processes, 112, 58-69.

Janis, I. L., \& Mann, L. (1977). Decision making: A psychological analysis of conflict, choice and commitment. New York: The Free Press.

Jones, E. E., \& Davis, K. E. (1965). From acts to dispositions: The attribution process in person perception. In L. Berkowitz (Ed.). Advances in experimental social psychology, (pp. 219-266). New York: Academic Press.

Jones, E. E., \& Nisbett, R. E. (1972). The actor and the observer: Divergent perceptions of the causes of the behavior. In E. E. Jones, D. E. Kanouse, H. H. Kelley, R. E. Nisbett, S. Valins, \& B. Weiner (Eds.), Attribution: Perceiving the causes of behavior (pp. 79-94). Morristown, NJ: General Learning Press.

Jost, J. T., Banaji, M. R., \& Nosek, B. A. (2004). A decade of system justification theory: Accumulated evidence of conscious and unconscious bolstering of the status quo. Political Psychology, 6, 881-919. 
Jost, J. T., \& Hunyady, O. (2002). The psychology of system justification and the palliative function of ideology. European Review of Social Psychology, 13, 111153.

Kahneman, D., \& Tversky, A. (1979). Prospect Theory: An analysis of decision under risk. Econometrica, 47, 263-291.

Kahneman, D., \& Tversky, A. (1982). The simulation heuristic. In D. Kahneman, P. Slovic, \& A. Tversky (Eds.) Judgment under uncertainty: Heuristics and biases (pp. 201-208). New York: Cambridge University Press.

Kelley, H. H. (1967). Attribution theory in social psychology. In D. Levine (Ed.), Nebraska symposium of motivation, 15. (pp. 192-240). Lincoln, NE: University of Nebraska Press.

Kenworthy, J. B., \& Miller, N. (2002). Attributional biases about the origins of attitudes: Externality, emotionality, and rationality. Journal of Personality and Social Psychology, 82, 693-707.

van Knippenberg, D., De Cremer, D., \& van Knippenberg, B. (2007). Leadership and fairness: The state of the art. European Journal of Work \& Organizational Psychology, 16, 113-140.

Leary, M. R., Tambor, E. S., Terdal, S. K., \& Downs, D. L. (1995). Self-esteem as an interpersonal monitor: The sociometer hypothesis. Journal of Personality and Social Psychology, 68, 518-530.

LeVine, R. A., \& Campbell, D. T. (1972). Ethnocentrism: Theories of conflict, ethnic attitudes, and group behavior. Oxford: Wiley.

Lickel, B., Hamilton, D. L., Wieczorkowska, G., Lewis, A., Sherman, S., \& Uhles, A. N. (2000). Varieties of groups and the perception of group entitativity. Journal of Personality and Social Psychology, 78, 223-246.

Lind, E. A., Kulik, C. T., Ambrose, M., \& de Vera Park, M. V. (1993). Individual and corporate dispute resolution: Using procedural fairness as a decision heuristic. Administrative Science Quarterly, 38, 224-251.

Lind, E. A., \& Tyler T. R. (1988). The social psychology of procedural justice. New York: Plenum.

Loomes, G., \& Sugden, R. (1982). Regret theory: An alternative theory of rational choice under uncertainty. The Economic Journal, 92, 805-824.

Maio, G. R., \& Haddock, G. (2007). Attitude change. In A. W. Kruglanski \& E. T. Higgins (Eds.), Social psychology: Handbook of basic principles (2nd ed., pp. 565-586). New York: Guilford Press.

Malle, B. F. (1999). How people explain behaviour: A new theoretical framework. Personality and Social Psychology Review, 3, 23-48.

Malle, B. F. (2006). The actor-observer asymmetry in attributions: A (surprising) meta-analysis. Psychological Bulletin, 132, 895-919.

Malle, B. F., \& Knobe, J. (1997). Which behaviors do people explain? A basic actorobserver asymmetry. Journal of Personality and Social Psychology, 72, 288304.

Miller, D. T., \& Ross, M. (1975). Self-serving biases in the attribution of causality: Fact or fiction? Psychological Bulletin, 82, 213-225.

O’Brien, L. T., \& Crandall, C. S. (2005). Perceiving self-interest: Power, ideology, and maintenance of the status quo. Social Justice Research, 18, 1-24.

Otten, S. (2002). "Me and us" or "us and them"? The self as a heuristic for defining minimal ingroups. In W. Stroebe \& M. Hewstone (Eds.), European review of social psychology (Vol 13, pp. 1-33). London: Psychology Press. 
Payne, J. W., Bettman, J. R., \& Johnson, E. J. (1992). Behavioral decision research: A constructive processing perspective. Annual Review of Psychology, 43, 87131.

Perreault, S., \& Bourhis, R. Y. (1999). Ethnocentrism, social identification, and discrimination. Personality and Social Psychology Bulletin, 25, 92-103.

Pettigrew, T. F. (1979). The ultimate attribution error: Extending Allport's cognitive analysis of prejudice. Personality and Social Psychology Bulletin, 55, 461-476.

Piliavin, J.A., Dovidio, J., Gaertner, S., \& Clark, R.D., III. (1981). Emergency intervention. New York: Academic Press.

Platow, M. J., Wenzel, M., \& Nolan, M. (2003). The importance of social identity and self-categorization processes for creating andresponding to fairness. In S. A. Haslam, D. van Knippenberg, M. J. Platow, \& N. Ellemers (Eds.), Social identity at work: Developing theory for organizational practice (pp. 261-276). East Sussex, UK: Psychology Press.

Pronin, E., Gilovich, T., \& Ross, L. (2004). Objectivity in the eye of the beholder: Divergent perceptions of bias in self versus others. Psychological Review, 111, 781-799.

Pronin, E., Kruger, J., Savitsky, K., \& Ross, L. (2001). You don't know me, but I know you: The illusion of asymmetric insight. Journal of Personality and Social Psychology, 81, 639-56.

Pronin, E., \& Ross, L. (2006). Temporal differences in trait self-ascription: When the self is seen as an other. Journal of Personality and Social Psychology, 90, 197-209.

Reeder, G. D., Pryor, J. B., Wohl, M. J. A., \& Griswell, M. L. (2005). On attributing negative motives to others who disagree with our opinions. Personality and Social Psychology Bulletin, 31, 1498-1510.

Robbins, J. M., \& Kreuger, J. L. (2005). Social projection to ingroups and outgroups: A review and meta-analysis. Personality and Social Psychology Review, 9, 32-47.

Ross, M., McFarland, C., \& Fletcher, G. J. O. (1981). The effect of attitude on the recall of personal histories. Journal of Personality and Social Psychology, 40, 627-634.

Ross, M., \& Shulman, R. F. (1973). Increasing the salience of initial attitudes: Dissonance versus self-perception theory. Journal of Personality and Social Psychology, 28, 138-144.

Ross, L., \& Ward, A. (1996). Naïve realism in everyday life: Implications for social conflict and misunderstanding. In E. S. Reed, E. Turiel, \& T. Brown (Eds.), Values and knowledge (pp. 103-135). Hillsdale, NJ: Erlbaum.

Rubin, M., \& Hewstone, M. (1998). Social identity theory's self-esteem hypothesis: A review and some suggestions for clarification. Personality and Social Psychology Review, 2, 40-62.

Russo, J. E., \& Carlson, K. A. (2002). Individual decision making. In R. Wensley \& B. Weitz (Eds.), Handbook of marketing. London: Sage Publications.

Russo, J. E., Carlson, K. A., Meloy, M. G., \& Yong, K. (2008). The goal of consistency as a cause of information distortion. Journal of Experimental Psychology: General, 137, 456-470.

Schweitzer, M. (1994). Disentangling status quo and omission effects: An experimental analysis. Organizational Behavior and Human Decision Processes, 58, 457-476. 
Simon, D., Snow, C. J., \& Read, S. J. (2004). The redux of cognitive consistency theories: Evidence judgments by constraint satisfaction. Journal of Personality and Social Psychology, 86, 814-837.

Skitka, L. J., Mullen, E., Griffin, T., Hutchinson, S., \& Chamberlin, B. (2002). Dispositions, scripts, or motivated correction? Understanding ideological differences in explanations for social problems. Journal of Personality and Social Psychology, 83, 470-487.

Smith, H. J., Tyler, T. R., Huo, Y. J., Ortiz, D. J., \& Lind, A. E. (1998). The selfrelevant implications of the group-value model: Group membership, self-worth, and treatment quality. Journal of Experimental Social Psychology, 34, 470-493.

Stephan, W. G., Boniecki, K. A., Ybarra, O., Bettencourt, A., Ervin, K. S., Jackson, L. A., \& McNatt, P. S. (2002). The role of threat in the racial attitudes of blacks and whites. Personality and Social Psychology Bulletin, 28, 1242-1254.

Ståhl, T., Van Prooijen, J. W., \& Vermunt, R. (2004). On the psychology of procedural justice: Reactions to procedures of ingroup vs. outgroup authoritites. European Journal of Social Psychology, 34, 173-189.

Svenson, O. (1992). Differentiation and consolidation theory of human decision making: A frame of reference for the study of pre- and post-decision processes. Acta Psychologica, 80, 143-168.

Svenson, O. (1996). Decision-making and the search for fundamental psychological regularities: What can be learned from a process perspective. Organizational Behavior and Human Decision Processes, 65, 252-267.

Svenson, O. (2003). Values, affect, and processes in human decision making: A differentiation and consolidation theory perspective. In S. L. Schneider \& J. Shanteau (Eds.). Emerging perspectives on judgment and decision research. Cambridge: Cambridge University Press.

Svenson, O. (2006). Pre- and post-decision construction of preferences: Differentiation and consolidation. In S. Lichtenstein \& P. Slovic, (Eds.) The construction of preference (pp. 356-371). Cambridge: Cambridge University Press.

Svenson, O., Ortega Rayo, A., Anderson, M., Sandberg, A., \& Svahlin, I. (1994). Post-decision consolidation as a function of the instructions to the decision maker and the decision problem. Acta Psychologica, 87, 181-197.

Svenson, O., \& Malmsten, N. (1996). Post-decision consolidation over time as a function of gain or loss of an alternative. Scandinavian Journal of Psychology, 37, 302-311.

Tajfel, H., Billig, M. G., Bundy, R. P., \& Flament, C. (1971). Social categorization and intergorup behaviour. European Journal of Social Psychology, 1, 149-178.

Tajfel, H. (Ed.). (1978). Differentiation between social groups: Studies in the social psychology of intergroup relations. London: Academic Press.

Tajfel, H., \& Turner, J. C. (1979). An integrative theory of intergroup conflict. In W. G. Austin \& S. Worchel (Eds.), The social psychology of intergroup relations (pp. 33-47). Monterey, CA: Brooks/Cole.

Tajfel, H., \& Turner, T. R. (1986). The social identity theory of intergroup behaviour. In S. Worchel \& W. G. Austin (Eds.), Psychology of Intergroup Relations (pp. 7-24). Chicago: Nelson-Hall.

Tansky, J. W. (1993). Justice and organizational citizenship behavior: What is the relationship? Employee Responsibilities and Rights Journal, 6, 195-207. 
Tesser, A. (1988). Towards a self-evaluative maintenance model of social behavior. In L. Berkowitz (Ed.), Advances in experimental social psychology (pp. 181227). Orlando, FL: Academic Press.

Thibaut, J., \& Walker, L. (1975). Procedural justice: A psychological analysis. Hillsdale, NJ: Erlbaum.

Todorov, A., Mandisodza, A. N., Goren, A., \& Hall, C. C. (2005). Inferences of competence from faces predict election outcomes. Science, 308, 1623-1626.

Turner, J. C., Hogg, M. A., Oakes, P. J., Reicher, S. D., \& Wetherell, M. (1987). Rediscovering the social group: A self-categorization theory. New York: Blackwell.

Tyler, T. R. (1990). Why people obey the law: Procedural justice, legitimacy, and compliance. New Haven, CT: Yale University Press.

Tyler, T. R. (1994). Psychological models of the justice motive: Antecedents of distributive and procedural Justice. Journal of Personality and Social Psychology, 67, 850-863.

Tyler, T. (2004). Affirmative action in an institutional context: The antecedents of policy preferences and political support. Social Justice Research, 17, 5-24.

Tyler, T. R., \& Blader, S. L. (2003). The group engagement model: Procedural justice, social identity, and cooperative behavior. Personality and Social Psychology Review, 7, 349-361.

Tyler, T. R., \& Degoey, P. (1995). Collective restraint in social dilemmas: Procedural justice and social identification effects on support for authorities. Journal of Personality and Social Psychology, 69, 482-497.

Tyler, T. R., Degoey, P., \& Smith, H. J. (1996). Understanding why the justice of group procedures matters: A test of the psychological dynamics of the groupvalue model. Journal of Personality and Social Psychology, 70, 913-930.

Tyler, T. R., \& Lind E. A. (1992). A relational model of authority in groups. In M. P. Zanna (Ed.), Advances in experimental social psychology, 25, (pp. 115-191). San Diego, CA: Academic Press

Vignoles, V. L., Regalia, C., Manzi, C., Golledge, J., \& Scabini, E. (2006). Beyond self-esteem: Influence of multiple motives on identity construction. Journal of Personality and Social Psychology, 90, 308-333.

Walster, E., Walster, G.W., \& Berscheid, E. (1978). Equity: Theory and research, Boston: Allyn and Bacon.

Wertheimer, M. (1923). Untersuchungen zur Lehre von der Gestalt II. Psychologische Forschung, 4, 301-350.

Williams, K. D. (2007). Ostracism. Annual Review of Psychology, 58, 425-452.

Willis, J., \& Todorov, A. (2006). First impressions: Making up your mind after 100 ms exposure to a face. Psychological Science, 17, 592-598.

Zanna, M. P., \& Rempel, J. K. (1988). Attitudes: A new look at an old concept. In A. W. Kruglanski \& D. Bar-Tal (Eds.). The social psychology of knowledge (pp. 315-334). New York: Cambridge University Press. 
